\title{
Information Processing Bias in Post-traumatic Stress Disorder
}

\author{
Darren L. Weber ${ }^{*}$
}

Dynamic Neuroimaging Laboratory The University of California, San Francisco, CA, USA

\begin{abstract}
This review considers theory and evidence for abnormal information processing in post-traumatic stress disorder (PTSD). Cognitive studies have indicated sensitivity in PTSD for traumatic information, more so than general emotional information. These findings were supported by neuroimaging studies that identify increased brain activity during traumatic cognition, especially in affective networks (including the amygdala, orbitofrontal and anterior cingulate cortex). In theory, it is proposed that traumatic cognition may interfere with neutral cognition and there is evidence of abnormal neutral stimulus processing in PTSD. Firstly, PTSD patients perform poorly on a variety of neuropsychology tasks that involve attention and memory for neutral information. The evidence from event-related potentials and functional neuroimaging also indicates abnormal results in PTSD during neutral stimulus processing. The research evidence generally provides support for theories of trauma sensitivity and abnormal neutral stimulus processing in PTSD. However, there is only tentative evidence that trauma cognition concurrently interferes with neutral cognition. There is even some evidence that traumatic or novelty arousal processes can increase the capacity for attentive processing, thereby enhancing cognition for neutral stimulus information. Research on this topic has not yet fully explored the mechanisms of interaction between traumatic and neutral content in the cognitive dynamics of PTSD.
\end{abstract}

\section{INTRODUCTION}

This review reconsiders theory and research on information processing in PTSD [see also 1-7]. There is an emphasis on cognitive and neuropsychological theories of PTSD, which are used to interpret research studies. The aim is to evaluate findings related to cognition and affect in PTSD, especially studies of brain activity related to attention and memory functions [see also 8-10]. This review considers studies of traumatic and neutral cognition in PTSD, which have often been two separate, yet complimentary, research domains. In essence, theory and research indicate that PTSD involves a shift in awareness towards traumatic cognition, at the cost of effective neutral information processing.

\section{CLINICAL PHENOMENA}

The impetus for PTSD is a life threatening experience, with intense, often overwhelming, horror, fear, or helplessness [11]. A traumatic experience can induce many of the most common psychiatric symptoms, such as stress, phobia, panic attacks, and depression [8]. The defining symptoms of PTSD are recurrent traumatic memories (including flashbacks and nightmares), trying to avoid traumatic cognitions (through withdrawal and emotional numbing), and hyperactive stress responses [11]. PTSD is a chronic and debilitating disorder, which persists beyond an acute stress reaction that resolves within three months [1114]. Some studies indicate that PTSD affects $15-30 \%$ of combat or disaster survivors $[15,16]$ and $18-42 \%$ of people with physical injuries [17].

*Address correspondence to this author at the Dynamic Neuroimaging Laboratory, University of California, San Francisco, 185 Berry Street, Suite 350, San Francisco, CA 94107, USA. Tel: +1 415 353-9444; Fax: +1 415 353-9421; E-mail: Darren.Weber@radiology.ucsf.edu
As many trauma victims do not develop PTSD, there must be important individual differences in susceptibility to the impact of trauma $[2,8,18,19]$. Susceptibility to PTSD is related to many factors (such as genetic risk, prior stressful events, and social support), yet most studies indicate the primary determinants of PTSD are the proximity, intensity, and duration of the traumatic event [11, 20-27]. If qualities of the traumatic experience are the most important predictors of PTSD, understanding how PTSD develops requires assessment of the trauma impact on stress physiology, affect appraisals and the integrity of cognitive systems [2, 18, 2832]. It is important to understand how the acute stress response is resolved, and to know more about the enduring cognitive and emotional changes that become PTSD [19].

\section{COGNITIVE THEORY OF PTSD}

Essentially, PTSD is a failure to resolve an intense emotional experience $[5,18,33]$. While adapting to life after trauma, PTSD patients suffer persistent, intrusive, recollections of the incident (i.e., reminders, vivid flashbacks and nightmares). Their traumatic memories can be triggered by any cues that resemble or symbolize the trauma, a process of associative conditioning that leads to anxiety and hypervigilance for such cues. Moreover, their traumatic recollections can occur in many neutral circumstances, lending greater potential for otherwise neutral cues to trigger intrusions, which increases the pressure to be vigilant for diverse cues. Hence, PTSD patients actively avoid any circumstances related to their trauma. Their avoidance can amount to an intense emotional numbing and withdrawal, including apathy for enjoyable activities and loss of empathy and intimacy with others.

Horowitz [33] identified these states of intrusion and avoidance as a necessary cyclical pattern of gradual 
adaptation to trauma, wherein extreme tension between these states may prolong the process of resolution. In PTSD, extreme avoidance can hinder adaptive interactions with new circumstances, leaving a person stuck in a trauma response pattern. In general, reconciliation to the traumatic event, and it's consequences, entails significant affective and cognitive dissonance [34]. A catastrophic experience conflicts with beliefs of safety or invulnerability, which can prompt a reassessment of personal security and the risks of danger in the environment. The persistent replay of traumatic memories may help to extract more information about exactly what happened and why it happened, which can be incorporated into a new world view that will shape future expectations and values [35].

This information is particularly important in the determination of causal attributions. Our understanding of the relationships between our actions and outcomes form a great part of our self efficacy [36-38]. It has been shown that habitual patterns of causal attribution are related to general motivation and affective dispositions, including helplessness and depression [39-41]. PTSD patients are likely to attribute causes for negative events to external, stable, and uncontrollable sources [42]. This lack of perceived control over negative life events may be related to low self-efficacy, helplessness and depression [43- 45]. PTSD patients also attribute the causes of positive events to external and uncontrollable sources [42]; they believe that positive experiences do not result from their own actions and, therefore, they cannot derive pride or self-esteem from their achievements. Coupled with fearful perceptions of the environment and expectations of uncontrollable danger, their hope and desire to act positively can waver. One study has shown that when PTSD patients confront stressful interpersonal relations, they tend to adopt an emotion focused strategy, rather than a more effective problem focused strategy, to resolve the difficulty [46, 47]. Rather than take action to remedy the situation, PTSD patients tend to withdraw into their feelings of distress and helplessness.

Recovery from trauma may depend critically on the capacity for attending to the present moment [48]. In 1889, French physician and philosopher Pierre Janet proposed that traumatic experiences remain encapsulated within their own psychic arena, dissociated from normal consciousness [4951]. He proposed that effective treatment requires translation of the traumatic representations into narratives, often through the use of hypnotic states that allow direct manipulation of the trauma experience. Moreover, he proposed it is important to encourage alternative, non-trauma mental states, mainly through developing the ability to interact with clarity and purpose in the present $[18,51]$.

The capacity for attending to the present is a process of directing and integrating sensory awareness, within a context of adaptive cognitive structures, to develop and carry out action plans. Efficient behavior in new circumstances involves integrating current experiences with abstractions from previous experiences, which provide general guidelines for prediction of outcomes in similar situations [52-56]. If there is any failure to develop and maintain the integrity of general cognitive schemata for everyday living, the difficulty in doing many ordinary activities increases, especially under stressful conditions.
A traumatic experience may disrupt cognition by not only evoking overwhelming emotions, but also failing to integrate into general cognitive schemata [2, 30, 57-60]. The trauma leaves a unique memory of salient perceptions, emotions, and reactions. As the traumatic event threatens survival, it can prompt persistent re-analysis to identify potential cues for future avoidance, and this traumatic rumination has been associated with PTSD [61]. However, it is a novel, unique experience, so there are few, if any, prior experiences for comparison, which makes it difficult to evaluate and understand the trauma. In addition, evaluation of trauma memories may be complicated because they lack the spatio-temporal coherence of most episodic memories [62]. The overwhelming emotion at the time of the trauma can provoke dissociative states that fragment the experience $[50,62]$. Also, the looming vulnerability experienced during a traumatic incident engages heightened levels of arousal, with implications for immediate action [63]. These hyperarousal states can engage sensory and action processes that bypass cognitive appraisal processes, which require more time to evaluate and integrate current perceptions with previous experiences. The intensity of the experience leaves strong sensory, affective and action memory traces that are particular to the traumatic experience. The circumstances of a trauma may be common, but the novel and threatening traumatic event can leave primary sensory, vivid snapshots of experience. The snapshots may be fragmented, as hyperarousal distorts perception during traumatic incidents. This may expose the temporal delays inherent in the perception process, which involves integration of information distributed across many parallel processing systems [64, 65]. Split-second perceptions and reactions can make the difference between life and death in traumatic situations. These fast perceptions and actions may be difficult to encode into coherent episodic memories [4]. The elements of traumatic experience are not easily translated into linguistic narratives, which usually require coherent causal relations among perceptions $[4,5,50,51]$. The intrusive re-experiencing of traumatic memories may continue to overwhelm normal cognitive states, which can perpetuate the fragmentation of traumatic cognitions. The repetitive memories can lead to sensitization and persistence of the traumatic experiences, with the potential for greater elaboration and consolidation across successive intrusions $[10,66]$. In PTSD there is a separation of traumatic from normal experience and the traumatic content becomes encapsulated into a particular trauma schema $[10,58]$.

Any activation of associations into their trauma schema can prompt PTSD patients to slip into a traumatic awareness, wherein it is more likely they will interpret current experiences in relation to their trauma. According to Chemtob et al. [58, p. 266], “. . . threat arousal inhibits the operation of other information-processing modes or schemata, thereby preventing their operation and further narrowing the attentional focus on threat-related stimuli." Their conception emphasises that traumatic cognitions dominate awareness, possibly within a dissociated state. It is also possible that traumatic cognitions, at some level, coincide with neutral cognitions. Nevertheless, the activation of traumatic schemata can develop higher expectations that threatening or traumatic events can occur. Hence, PTSD patients should be more susceptible to interpret ambiguous 
or novel events as threatening, so their stress responses could be more consistently elevated in new circumstances. This sensitivity to ambiguity or novelty can distract attention from current activities, which interrupts the development of cognitive structures for relating to neutral circumstances.

\section{TRAUMA SENSITIVITY}

This section reviews traumatic information processing in PTSD [see also 1, 3, 60]. The research demonstrates greater attention and stress responses for traumatic information in PTSD. This section can be compared with the following sections, which review neuropsychological theory and neuroimaging studies of neutral information processing in PTSD.

\subsection{Cognitive Psychology}

\subsubsection{Attention to Threat}

Trandel and McNally [67] investigated unconscious threat sensitivity in Vietnam veterans (15 combat veterans with PTSD, 15 non-combat veterans with alcohol dependence, and 15 noncombat veterans; groups were matched for race, age, and education). In a dichotic listening task, the veterans repeated a series of neutral words presented to their right ear (unrelated neutral words were used to minimize semantic associations). The simultaneous series in the left ear contained words from the following four categories: threatening words for Vietnam veterans, words phonemically similar to those words, threatening words for agoraphobics and obsessive-compulsives, and neutral words. Trandel and McNally [67] measured unconscious processing as the number of times that veterans made an error on the next word after they correctly repeated a word that was paired with a threatening word in the left ear. In this case, there is no immediate shift of conscious attention to the threatening word in the left ear, but a degree of unconscious semantic processing that interferes with listening to the following neutral word in the right ear. The results indicated that PTSD patients had only a few more errors than other subjects after the presentation of threatening words (statistical analysis revealed no significant group differences in errors). Trandel and McNally [67] also hypothesized that unconscious processing of threatening words should be associated with autonomic arousal, but there were no significant group differences in skin conductance related to threatening words. These findings may be partially attributed to the low sensitivity of their study, they presented only seven threatening words among a series of 3,600 words.

It is difficult to assess automatic semantic processing in dichotic listening tasks. Trandel and McNally [67] assessed unconscious interference with shadowing, but the requirement that unconscious processing should not be associated with errors in shadowing the current word presentation strictly limits the evaluation of automatic processes. It may be possible that automatic semantic processing interferes with concurrent shadowing by provoking conscious awareness of meaning, so a strict constraint of the evaluation of unconscious automatic semantic processing is required in the dichotic listening task [68]. Although PTSD patients may not be unconsciously processing threatening information, this does not imply that they are not susceptible to automatic processing of threatening information. Sensitive threat-related sensory, perceptual, or semantic representations may respond automatically to threatening information and facilitate conscious awareness of that information [68]. In threatening situations, such as combat, automaticity of complex reflex actions and diversion of cognitive resources to deal with danger can make the difference between life or death.

Another method to investigate automatic threat processing is an affective Stroop task -it involves naming the printed color of words with affective similarity to the symptoms of psychopathology [69]. Automatic semantic encoding and associative processing can stimulate affective responses, which can interfere with the primary task of naming the word color [68]. Stroop interference related to threatening information reflects automatic activation of threat-related semantic and affective associations, including avoidance processes.

Studies of a modified Stroop task demonstrate greater attention for traumatic words in PTSD. For example, Cassiday, Mc-Nally, and Zeitlin [70] examined affective Stroop interference in victims of sexual assault with PTSD, without PTSD, and a normal control group (groups were matched for race, sex, age, and education; the mean time since trauma was 9.42 years, with a range of $0.3-34.0$ years). The task comprised colored words from four word types: high threat (rape, penis), moderate threat (emergency, crime), positive (love, happy), and neutral (polite, moderate). These words were randomly presented in either a mixed manner or blocked according to word type (neutral, positive, moderate-threat, and high-threat, in that order). For the neutral and positive words, color naming was slower during the mixed series than the blocked stimuli, but responses for high and moderate threat words were unaffected by the presentation format. In general, PTSD patients responded slower to high-threat words than moderate-threat and positive words, which they were slower to respond to than neutral words. Also, PTSD patients responded slower to high-threat, moderate-threat, and positive words than all other subjects. Similarly, rape victims without PTSD were slower to respond to high-threat words than other words and they were slower to respond to high-threat words than normal control subjects. Furthermore, response latency for high-threat words in all rape victims was significantly associated with the intrusion sub-scale, but not the avoidance sub-scale of the Impact of Events Scale (IES). Many rape victims without PTSD had previously qualified for a diagnosis of PTSD and the results indicate that they had a residual sensitivity for stimuli related to their traumatic experience, suggesting that the cognitive schemata associated with a traumatic experience can persist for some time after the remission of PTSD symptoms. Since the sensitivity for threatening information was associated with intrusions, the primary symptom of PTSD, it is not surprising that the rape victims with chronic PTSD demonstrated slower responses than rape victims without PTSD to the high-threat words, suggesting they have a greater sensitivity or coherence of their trauma representations. Most importantly, this study shows that the presence of traumatic information in the mixed blocks interfered with color naming of the neutral words, providing important research evidence to support the contention that trauma and threat sensitivity actually interferes with neutral 
stimulus processing [58]. These findings of threat sensitivity in the affective Stroop task pertain to PTSD resulting from various trauma, including Vietnam combat [71], sexual assault [70, 72], a ferry disaster [73] and motor vehicle accidents [74]. Most of these studies support the hypothesis that PTSD patients have a sensitive threat-related schema, which is different from that of other anxiety disorders, but the generality of their trauma schema may be restricted to information that is closely associated with the original threatening experience [74]. In most of these studies, trauma sensitivity is positively associated with the severity of PTSD symptoms, especially traumatic intrusions [70, 71]. Furthermore, there is residual sensitivity after recovery from PTSD; so although symptoms abate, the underlying trauma schema persists $[70,73]$.

\subsubsection{Memory for Threat}

Several studies demonstrate memory biases for traumatic information [75-79]. For example, Zeitlin and McNally [75] assessed implicit and explicit memory for threat-related information in PTSD. They hypothesized that PTSD patients have an active threat schema, such that implicit and explicit memory for threatening information will be greater in PTSD. They evaluated Vietnam combat veterans with $(n=24)$ and without $(n=24)$ PTSD. Subjects were not matched for age, education, or combat exposure, but there was no significant influence of age or education on recall. They were presented with a list of words, related to combat, social threat, and positive or neutral affect. Half of the subjects were required to rate how much they liked each word (elaborate encoding) and half of the subjects were required to count the letters in each word (feature encoding). After counting backwards, subjects performed a word stem completion task with the first word that comes to mind (implicit memory) and a cued recall task with a word that was seen earlier (explicit memory). Half of the word stems in the implicit and explicit memory tasks were presented during encoding, so memory performance could be assessed for both primed and unprimed words. Combat veterans with PTSD recalled fewer neutral and positive words than combat veterans without PTSD. Zeitlin and McNally [75] propose that this reflects a lack of attention to this information, since cognitive resources are utilized to process or avoid processing threatening information. This information processing bias was reflected in recall; relative to recall for neutral words, PTSD patients recalled more combat words than combat veterans without PTSD. The recall for combat words was significantly associated with combat exposure. Since combat veterans with PTSD had more combat exposure than combat veterans without PTSD, this recall bias may be attributed to either greater combat exposure or PTSD. However, combat veterans with PTSD had an implicit memory bias for unprimed combat words, which was enhanced by priming. This implicit memory bias was significantly associated with the severity of PTSD after controlling the degree of combat exposure. Thus, an implicit bias for combat words in combat veterans with PTSD reflects a chronic activation of elaborate and stable sensory, perceptual or semantic memories for combat experiences in the PTSD group. The activation of these unconscious representations will easily promote conscious awareness of the trauma information. Thus, the intrusions of combat veterans with PTSD may result from a heightened activation or sensitization of unconscious combat memories.

These memory biases apply to episodic memories of events and also autobiographical memories [76, 77]. For example, McNally et al. [76] investigated episodic memory for personal experience of positive and negative affect in Vietnam combat veterans with PTSD $(n=39)$, veterans with other psychiatric conditions $(\mathrm{n}=20)$, and veterans without psychiatric morbidity $(n=23)$. Subjects were presented with a short series of either furniture pictures (accompanied by classical piano) or Vietnam combat pictures (accompanied by combat sounds). Subjects rated their moods before and after the presentations. Also, after the presentations, subjects recalled a personal experience of some specific emotions, including positive states (e.g., comradeship, humor, devotion, gaiety, intimate, kindness, happiness, loyalty, affection, and bravery), negative states (e.g., boredom, sickness, anxiety, misery, fatigue, shame, panic, sadness, ignorance, and hostility), and neutral states (e.g., mathematics, amazement, background, determination, reflection, illusion, hierarchy, agreement, gravity, and appearance). Relative to furniture pictures, the pictures of Vietnam combat reduced happy, positive mood states and increased negative mood states (anxiety, anger, emotional arousal). Among veterans with PTSD, veterans exposed to combat pictures recalled more episodes of neutral affect, but not positive or negative affect, than veterans exposed to furniture pictures (this could reflect a process of emotional numbing). Veterans without morbidity reported more episodes of positive or negative emotion than neutral affect, veterans with other psychiatric conditions reported more experiences of negative affect than neutral affect, and veterans with PTSD recalled more experiences of negative than positive emotion. In general, veterans with PTSD were less specific than veterans without morbidity and they recalled more negative and Vietnam memories. Veterans with PTSD had higher levels of depression, anxiety, and combat exposure than other subjects. These results indicate that veterans with PTSD have difficulty recalling specific emotional experiences, but when they do recall emotional experiences, they are more often about negative or traumatic experiences. This bias in recollection may play an important role in the onset and maintenance of PTSD symptoms, so any increase in the recall of positive personal experience may counteract the bias and alleviate symptoms of PTSD [76]. In another study, McNally et al. [77] found that Vietnam combat veterans with PTSD have a deficit in their focus of attention or episodic memory for specific experiences of positive feelings about themselves. Most people focus on positive personal attributes more so than negative personal attributes, but veterans with PTSD have no such bias. This could be related to disturbances in selfrepresentation and affect, including low self-efficacy, guilt, sorrow, and numbing of positive emotional experience [77] [see also 40].

\subsection{Cognitive Electrophysiology}

Event-related potentials (ERPs) are employed to measure brain responses to specific events, often auditory and visual stimuli, with a high temporal resolution $(\mathrm{msec})$. The stimulus evoked responses, such as the P50 and P1/N1/P2 complex, indicate early stages of processing in sensory pathways and 
cortical areas (within $100 \mathrm{msec}$ ), while later endogenous ERPs, such as the N2/P3 complex, indicate more complex cortical processing. The activity indicated by these ERPs is modulated by cognitive processes such as attention and memory [80-93]. Cognitive ERP studies investigate the components of sensory processing and attention that are affected by trauma sensitivity in PTSD. These biological indices provide insight into the stages of information processing, from sensation to perception and memory, that are activated by traumatic information in PTSD [see also 94].

Attias, Bleich, and Gilat [95] investigated sensitivity to trauma in Israeli combat veterans using a visual oddball task with common pictures (furniture and flowers, 60\%), rare target pictures (domestic animals, 20\%) and rare combat pictures $(20 \%)$. Combat veterans with PTSD had larger N1 and P3 amplitudes and shorter P3 latency for the combat pictures [see also 96, 97]. An increase in N1 amplitude may reflect an early, automatic allocation of attention to identification and discrimination of the physical attributes of stimulus information; in this case, it suggests that PTSD patients automatically orient to traumatic images. In addition, larger P3 amplitude for combat pictures indicates greater attention to evaluation of the significance or meaning of the traumatic images, which depends on prior exposure and sensitivity to their traumatic content. Also, P3 latency for traumatic images was positively associated with the frequency of traumatic intrusions. Furthermore, a discriminant function, based on P3 amplitude in response to combat pictures alone, correctly identified $85-90 \%$ of veterans with PTSD and 95\% of veterans without PTSD. These results clearly indicate sensitivity to traumatic information in PTSD, at several levels of attentive processing.

However, these effects were not entirely specific to traumatic information. The P3 activity in PTSD was enhanced for both neutral targets and combat distracters; controls had larger P3 activity for neutral targets than combat images [96]. Also, there was some indication that traumatic images might interfere with processing neutral targets, because there was delayed P3 and reaction times for the neutral targets in PTSD [96]. These results may provide partial support for the theory that activation of a trauma schema in PTSD can enhance traumatic, but interfere with neutral information processing $[58,59]$.

Several studies have investigated the sensitivity of PTSD patients to both traumatic and non-traumatic emotional stimuli [98, 99] [see also 100]. Firstly, Kounios et al. [98] reported an ERP study of visual word stimuli that comprised common words (neutral or combat related) and rare target words (foods). Their findings indicate larger P3 amplitude for both combat and neutral words in PTSD (there was no difference in P3 activity between combat and neutral words). As in the previous work [96], this study also indicated larger P3 for all stimuli in the presence of traumatic stimuli. It is interesting that the frequency of combat stimuli was not a significant factor in eliciting enhanced responses; Attias et al. [96] presented combat stimuli rarely, whereas Kounios et al. [98] presented frequent combat stimuli. Also, there appear to be no substantial differences between pictorial and word stimuli. In contrast, Stanford et al. [99] observed greater $\mathrm{P} 3$ activity for trauma words and smaller P3 activity for neutral words in PTSD patients. They observed an enhanced frontal P3 for trauma words [it was specific to trauma, it did not generalize to social threat words; cf. 79]. Thus, while these studies to date confirm enhanced responses to trauma in PTSD, they are inconclusive with respect to associated effects on concurrent neutral information [cf. 58, 59].

However, even this conclusion is compromised by one ERP study of emotional Stroop words, which indicated smaller and later P3 activity for all words in PTSD patients, even for trauma words [101]. For all combat veterans, this study confirmed delayed reaction times for traumatic words, which has been observed in emotional Stroop studies [e.g. 71]. It also demonstrated that trauma words are related to greater frontal P3 than neutral words (for both PTSD and control subjects). This larger frontal P3 may confirm that delayed responses to emotional Stroop words reflect greater attention for the emotive words. However, the PTSD subjects had smaller and later parietal P3 ERPs than control subjects, so the PTSD patients were not evaluating those words as much as control subjects. This finding is inconsistent with the previous literature and theory on attention bias in PTSD, which clearly predicts greater responses for trauma words in PTSD. A large proportion of research findings appear to support this hypothesis, so it is difficult to reconcile this study with both theory and previous work. Perhaps the differences between studies reflect variations in the degree of intrusive or avoidance symptoms in patients or the nature of control groups. The differences might also depend critically on the absolute or relative frequency of presentation for neutral, emotive, threat, or trauma stimuli [c.f. 97]. Also, the nature of the stimulus information may be critical; perhaps PTSD patients are more sensitive to visual or auditory sounds associated with trauma than linguistic associations [50]. Further independent replication of this study would be valuable, with further consideration of intrusive and avoidance symptoms, control subjects, and frequency of stimulus presentations.

Kounios et al. [98] also found smaller P100 ERP amplitude over the right posterior temporal region in PTSD, for a series of visual words that contained traumatic and neutral words (the observed effects were not differentiated for traumatic and neutral words). Their results indicate that there are diminished early visual responses for all words in the presence of traumatic information. The findings of Kounios et al. [98] are inconsistent with previous reports of enhanced N1 activity for combat pictures [i.e., 95, 96]. Thus, their results also indicate there are decreased responses during early processing of visual word stimuli in PTSD, even if the stimuli are traumatic.

\subsubsection{Emotional Generalization}

If the sensitivity to traumatic information is a general, reliable finding, it could be due to general emotional arousal, not necessarily related to traumatic information. Blomhoff, Reinvang, and Malt [102] investigated responses to emotional words in PTSD. They used an auditory P3 oddball task that comprised standard tones $(800 \mathrm{~Hz}, 60 \%)$, target tones $(1200 \mathrm{~Hz}, 20 \%)$, and distracters generated from spoken words $(20 \%)$. In separate task blocks, the distracters were 
either non-words or words of negative or positive emotion ${ }^{1}$. They proposed that any emotional words could be associated with traumatic arousal, so they will capture attention and elicit larger P3 activity. Moreover, the emotional words (especially negative words) should distract attention from the primary task and lead to smaller P3 activity for target events, especially for PTSD patients. The P3 amplitude for targets suggested less activity in PTSD for all distracter conditions, but the statistical analysis found no significant group differences (the study may lack power to detect these effects due to a small sample size). Analysis of the ERP activity for the distracter stimuli indicated biphasic P3 activity, with a larger peak at $160-280 \mathrm{msec}$ followed by a smaller peak at $280-420 \mathrm{msec}$ (it was clearest for negative words). The P3 activity was larger for emotive than for non-word distracters between 150-300 msec for all subjects. At the group level, there were no significant differences in the P3 responses to emotive distracters (after subtracting the responses for nonwords). The initial conclusion from these analyses was that the ERP activity for target tones and for emotive distracters was normal in PTSD. However, there were significant associations between P3 activity for emotive words and PTSD symptoms (measured for all subjects, controlling for variance explained by non-words). For positive words, there was a positive association for posterior P3 activity at 150 $300 \mathrm{msec}$ with both arousal and avoidance. For negative words, there was a positive association between arousal and P3 activity at $300-450 \mathrm{msec}$ in right frontal and posterior regions. For all emotive words, there was a positive association between avoidance and frontal P3 activity at 300$450 \mathrm{msec}$ (this could mean that avoidance is related to greater semantic processing for emotive words, rather than inhibition of processing). Essentially, these results indicate that P3 activity for emotional information is related to arousal and avoidance symptoms, but not intrusive symptoms, in trauma victims. On the basis of these multivariate regression analyses, this study provides tentative evidence that trauma sensitivity can generalize to any emotional words. It is not known whether these findings for auditory emotive words also apply to visual images. Given some hypotheses about abnormal linguistic functions in PTSD, the strength of a general emotive sensitivity may be clearer for visual images in PTSD.

Although Blomhoff et al. [102] employed a valuable task design, the study could not control for important diagnostic criteria. It was limited to a small sample of ship disaster survivors, where most but not all patients satisfied all the criteria for PTSD and many of them had comorbid depression. Also, the control group were disaster survivors and some of them met criteria for depression also. Avoidance, emotional numbing and depression in PTSD patients may decrease their P300 responses to emotive stimuli [see also 103-105]. Also, some evidence indicates that depression is related to abnormal P300 activity [106110] [see also 111, 112]. Furthermore, it is not clear whether PTSD patients and controls were matched for demographic and psychometric qualities, such as intelligence. Hence, the

\footnotetext{
'Negative words included 'anger', 'sadness', 'anxiety'; positive words included 'joy', 'contentment'; and nonwords were reversed negative words (complex, meaningless stimuli). Each word was recorded by a male speaker, with a duration of 500-1000 msec. All stimuli presented at $95 \mathrm{~dB}$.
}

results of the study are tentative, pending a sound replication.

In a study of responses to emotive faces, Felmingham et al. [113] employed ERPs at occipital and posterior temporal scalp sites to measure early cortical responses to emotive faces (angry and neutral faces). They did not use a masked presentation; instead they presented alternating angry and neutral faces, with only passive viewing required. They reasoned that automatic emotive responses could induce a feedback modulation of visual cortical processing in striate and extrastriate face perception regions. Prior studies of normal subjects identified enhanced responses to emotive stimuli between 80-160 ms over fronto-central and posterior scalp regions. Similarly, Felmingham et al. [113] identified an enhanced negative peak at $110 \mathrm{~ms}$ over occipital and posterior temporal sites for angry vs. neutral faces in control subjects. These ERP components were smaller and slower for PTSD patients, and they did not discriminate between the angry and neutral facial expressions [113]. Felmingham et al. [113] interpret these findings as a refutation of the generalized threat sensitivity hypothesis in PTSD. Rather, they propose the findings are explained by a general failure of sensory discrimination processes.

While this may be true, another possibility is that sensory processing of all stimuli in this study were inhibited by topdown avoidance processes, given that stimuli were regular, predictable and they were not masked [cf. 114]. This could be consistent with both generally smaller amplitude and later peak activity of even the early visual ERP components. As in the study of Shin et al. [115, see below], passive viewing of threat or trauma images may not reveal enhanced responses in PTSD patients, who are likely to engage avoidance processing strategies. Rather, the enhanced sensitivity to threat and trauma stimuli appears to be a transient effect for masked and rare novel stimuli [114], which may escape topdown avoidance processing and engage novelty attention processes. The only other paradigm to elicit enhanced responses is script-driven imagery, which requires voluntary sustained attention for traumatic emotions and cognitions [e.g., 114, see below].

The aversive sensitivity in PTSD appears to be specific to the trauma, but tentative evidence suggests otherwise. Further evidence is required to explore whether traumatic sensitivity can be explained by a general emotional sensitivity. The work should characterize whether there is simply an associative generalization of traumatic sensitivity or a more pervasive emotional disturbance [see also 99, 103, 116].

\subsection{Cognitive Neuroimaging}

Functional neuroimaging includes measures of regional cerebral blood flow (rCBF) from positron emission tomography (PET) and functional magnetic resonance imaging (fMRI). There are now several studies of rCBF during traumatic cognition in PTSD $[114,115,117$ ] [see also $3,50,118]$.

Rauch et al. [114] used PET to investigate rCBF in PTSD during imagination of either traumatic or neutral experiences, prompted by listening to a tape recording of their own narration. For this traumatic script-driven imagery, 
PTSD patients had increased $\mathrm{rCBF}$ in limbic and paralimbic structures of the right hemisphere, including medial orbitofrontal, anterior cingulate, insular, and anterior and medial temporal cortex, as well as the amygdala [114] [see also 119]. The orbitofrontal cortex and the anterior cingulate are engaged in the appraisal of emotional experience and monitoring conflicting demands $[120,121]$. The amygdala, in particular, is involved in detection of threat and generation of fear, anger and associated autonomic and neuroendocrine responses [122, 123]. Another increase in rCBF was identified in secondary visual cortex, possibly related to traumatic visualization. In contrast, decreases in rCBF were found in left inferior frontal cortex (Broca's area) and left middle temporal cortex, suggesting decreased linguistic cognitions during traumatic imagery $[114,115]$ [see also 50, 124, 125].

These seminal findings were explored further by Shin et al. [115], who investigated rCBF during (a) imagery of trauma, negative and neutral experiences and (b) visual presentations of trauma, negative and neutral stimuli (which were accompanied by an auditory description of the scene). This study did not identify increased activity in PTSD for combat pictures, compared with neutral pictures. Rather, there was decreased activity for PTSD patients in left middle frontal and anterior cingulate cortex. In contrast, the combat veterans without PTSD demonstrated increased activity for combat pictures in left middle frontal gyrus, Broca's area, left superior temporal gyrus and left supramarginal gyrus (which may indicate greater auditory-verbal processing for the emotive combat pictures).

These findings of Shin et al. [115] are inconsistent with those to be expected, given theory on trauma sensitivity and prior findings of enhanced trauma responses in ERP studies [e.g., 95]. Perhaps the findings reflect avoidance in the PTSD patients. The PET procedure for blocked stimulus delivery is a continuous presentation of combat imagery, which may evoke an avoidance state in the PTSD subjects. For example, Bleich [97] observed that PTSD patients avoid processing repeated traumatic stimuli. They found that repeated combat pictures resulted in a rapid reduction in $\mathrm{P} 3$ amplitude and an increase in P3 latency for PTSD subjects. In most ERP tasks, traumatic images are rare and they occur among various image classes, which reduces or eliminates the effects of repetition suppression. Hence, a possible explanation for these results of Shin et al. [115] may be that PTSD subjects avoid the repetitive traumatic stimuli (perhaps a single-trial fMRI design could be adopted to evaluate this).

Another component of the work from Shin et al. [115] was a mental imagery condition, where patients voluntarily engage traumatic cognitions. In this study, there was increased anterior cingulate activity in PTSD for combat imagery, compared with neutral imagery; a confirmation of the previous findings [114]. Furthermore, comparison of responses to combat imagery versus combat pictures revealed enhanced activation in the left hemisphere, including the middle frontal gyrus, ventral anterior cingulate gyrus, and the supramarginal gyrus. There was also enhanced activation in the right amygdala. This suggests that previous findings of anterior cingulate and amygdala activity for traumatic imagery [114] could be specific to the voluntary generation of traumatic cognitions.

Further work has confirmed enhanced responses in the amygdala for fearful expressions. Rauch et al. [126] investigated fMRI of combat PTSD during a masked facial presentation, where facial expressions were either fearful or happy. These emotive faces were displayed very briefly (30 $\mathrm{ms}$ ) and then masked by a longer neutral face expression $(170 \mathrm{~ms})$. This task design prevents controlled processing of the masked faces, thereby activating automatic emotional responses, with enhanced activity in the amygdala for the fearful faces. The results clearly demonstrated greater activation of the left amygdala for fearful faces, with PTSD patients demonstrating larger activity than combat veterans without PTSD [126] [see also 113].

\subsection{Psychophysiology}

The activation of a trauma schema is associated with a peripheral fear or stress response and the feedback from that response reinforces the impact of the initial cognitive and affective appraisal. Psychophysiology studies of PTSD indicate that traumatic cues and mental imagery are often related to heightened startle responses and peripheral hyperactivity, including increases in heart rate and blood pressure, muscle tension, and skin conductivity [127-139].

Several research groups have pursued the use of objective measures of physiological arousal, in response to traumatic stimuli, to discriminate war veterans with and without PTSD. In a series of studies, Blanchard and colleagues have successfully discriminated veterans with or without PTSD on the basis of heart rate responses to combat sounds [62\% correct [128]; $95 \%$ correct for veterans with PTSD and non-veteran controls [127]; 75\%-83\% correct [134]; $81 \%$ correct [140]; $86.4 \%$ correct [129]; [see also 141, 142]]. They measured physiological responses to three conditions: (a) resting, (b) mental arithmetic, and (c) a combination of music, silence, and combat sounds that increase in loudness from 40 to $80 \mathrm{~dB}$, in steps of $20 \mathrm{~dB}$.

Blanchard et al. [134] found that a discriminant function, based on heart rate alone, correctly identified $84 \%$ of combat veterans with PTSD and $75 \%$ of all veterans. Furthermore, the same discriminant function correctly identified $83 \%$ of another sample of combat veterans with or without PTSD. Gerardi et al. [140] reported this discrimination has good short term test-retest reliability. Also, they reported that veterans with PTSD cannot consciously lower their physiological responses, so they appear to be without PTSD [cf. 139]. Also, although veterans without PTSD can elevate their responses to combat stimuli, it is still possible to discriminate them from veterans with PTSD with $85 \%$ accuracy using a discriminant function based on heart rate measures alone. Also, Casada [141] found that heart rate, more than electrodermal activity, was the most specific indicator of physiological arousal for traumatic content in PTSD.

In contrast, Pitman et al. [130] found that electrodermal activity was a better indicator of PTSD than heart rate. They assessed heart rate, forehead electromyogram (EMG), and skin conductance in response to unique combat incidents recollected by combat veterans. Independent raters agreed 
that the traumatic content and severity of the events recalled were similar for veterans with or without PTSD. The physiological response to the unique combat imagery was greater in veterans with PTSD than veterans without PTSD. In particular, skin conductivity $(73 \%)$, rather than forehead EMG $(67 \%)$ or heart rate $(64 \%)$, provided the best predictive discrimination of veterans with or without PTSD. A stepwise discriminant function, based on all three measures, correctly classified all PTSD veterans. While the sensitivity was excellent, the specificity was not perfect; it had $79 \%$ accuracy for all veterans with or without PTSD. Also, physiological arousal was associated with the frequency of intrusions related to those traumatic events. Pit-man et al. [130] proposed that veterans with PTSD were "reliving" their traumatic experiences, whereas veterans without PTSD were merely "recollecting" their experience [cf. 139].

The discrepancy in the predictive value of skin conductance and heart rate between the research studies above might be partially explained by an increase in skin conductivity to specific traumatic imagery. Pitman et al. [130] found that skin conductance, but not heart rate, was greater in response to specific combat imagery than general combat imagery [see also 139]. There is contradictory evidence, however, in the results of Casada [141], which indicate that heart rate, more so than skin conductance, is a more specific indicator of traumatic arousal in PTSD [see also 139, 142].

Brende [143] reported that skin conductivity in response to traumatic imagery reflects the functioning of the contralateral hemisphere and that the left and right hemisphere play different roles in the symptoms of PTSD. Skin conductivity from the right hand is associated with hypervigilance and emotional numbing in PTSD and it reflects the function of the left hemisphere, which is related to logical, linguistic operations on information from the senses and the maintenance of high levels of vigilance for changes in stimulation [143]. The relationship between hypervigilance and emotional numbing is not very clear. It could be expected that hypervigilance will produce irritability and volatile emotions rather than numbness. However, Brende [143] asserts that hypervigilance in the left hemisphere could involve lateral inhibition of the emotional processing of the right hemisphere. Conversely, skin conductivity from the left hand reflects the activity of the right hemisphere, which processes or regulates traumatic imagery and its emotional impact in PTSD [143]. Thus, skin conductivity may not only indicate the degree of physiological arousal, but also the functional specificity of the left and right hemispheres during traumatic imagery.

The findings of Pitman et al. [130] and Brende [143] suggest that skin conductance biofeedback could be useful in the treatment of PTSD [see also 137]. This biofeedback could help PTSD patients to control their physiological arousal, to decrease their anxiogenic feedback. The ability to reduce anxious physiological responses to traumatic imagery could be an important aspect of the recovery process. For instance, Boudewyns and Hyer [144] used the physiological assessment technique of Pitman et al. [130] and found that therapeutic reductions in symptoms are associated with decreases in heart rate and especially skin conductance responses to traumatic imagery immediately after therapy.
Boudewyns and Hyer [144] also reported that an exposure or flooding therapy reduces heart rate and skin conductance responses to traumatic imagery.

Murburg [145] points out interesting peripheral relationships to central processes. For instance, traumatic visualizations may induce increased peripheral epinephrine concentrations that increase memory consolidation by stimulating the amygdala, which is important in emotional stimulus evaluation and memory [see also 146, 147]. Also, "responding to a stressor . . . may itself leave behind molecular 'memory traces' that so alter involved neural pathways as to predispose them to be more readily activated in the future" [145, p. 354]. Reduction of peripheral hypersensitivity during psychotherapy promotes recovery from PTSD, which highlights the importance of visceral reinforcement for the maintenance of traumatic schemata [144] [cf. 32, 148].

\subsection{Summary}

These research studies have demonstrated sensitivity to traumatic information in PTSD, which is apparent in both neurocognitive and peripheral responses. Cognitive studies demonstrate traumatic sensitivity in attention and memory tasks, which is positively associated with intrusive symptoms. ERPs are enhanced for traumatic stimuli during both early sensory (N1) and later stimulus evaluation (P3) processes. ERPs also indicate that PTSD patients fail to discriminate relevant targets from irrelevant traumatic distracters. The ERP studies do not indicate sensitivity for emotional information in general, the sensitivity appears to be specific to trauma. Stimulus novelty is an important aspect of research design, several ERP studies indicate greater novelty responses in PTSD, even for non-traumatic stimuli. Some studies do not demonstrate sensitivity to traumatic stimuli, possibly due to extended traumatic presentations that evoke avoidance strategies; the sensitivity to trauma may be observed only for brief trauma stimuli or voluntary traumatic imagery. Neuroimaging during voluntary traumatic imagery demonstrates increased activity in limbic and paralimbic areas (the amygdala, medial orbitofrontal, anterior cingulate, insular, and anterior and medial temporal cortex). These areas are engaged in emotional evaluation, learning and memory. Peripheral stress feedback into these areas may serve to maintain and consolidate trauma sensitivity.

\section{NEUROPSYCHOLOGY MODELS OF PTSD}

In addition to the cognitive models of PTSD, there is a substantial literature on biological models of PTSD [see overview in 149]. Kolb [66] proposed a seminal theory to explain intrusive memories and associated arousal in PTSD. He started from a two factor learning theory that PTSD results from both classical conditioning of extreme emotional responses to traumatic stimuli (i.e., fear, terror, anger, rage, sadness, guilt, and indignation) and operant conditioning of emotional numbing, withdrawal, and avoidance of traumatic stimuli. Kolb [66] also proposed that PTSD involves excessive traumatic stimulation that overwhelms efficient information processing;

Such stimulus overload occurs when the ... capacity to process information signaling 
threat to life overwhelms the cortical ... processes concerned with perceptual discrimination and effective adaptive responses for survival [66, p. 993].

Excessive threatening stimulation sensitizes neuronal circuits that are responsive to threat, including structures in the "temporal-amygdaloid complex concerned with agonistic behavior", which may "lead to depression [or atrophy] of those synaptic processes which permit habituation and thus discriminative perception and learning" [66, p. 993]. As a result of this initial sensitization and a diminished capacity for discrimination, sensitivity to threatening stimuli generalizes, via a process of higher order conditioning, from an initial traumatic experience to a variety of similar threatening situations [66]. Furthermore, Kolb [66] proposed that this generalized sensitivity to threatening situations perpetuates agonistic affect, such that limbic activity disrupts frontal executive systems; in particular, the frontal systems that inhibit the locus ceruleus and its noradrenergic innervations of diverse cortical and subcortical structures. A possible increase in cortical and subcortical noradrenergic activation further enhances the sensitization and activation of the trauma schema [66] [see also 150]. As a result,

in the face of perceived threats there occurs excessive sympathetic arousal -including neuroendocrine disturbances as well as behavioral expressions of rage and irritability and repetitive cortical reactivation of memories related to the traumatic events. The latter are projected in the daytime as intrusive thoughts and at nighttime in the recurrent traumatic nightmares of PTSD ... [66, p. 994].

From an evolutionary perspective, it is adaptive to respond to ambiguous or threat stimuli with intense and rapid stress reactions in dangerous situations, but the persistence of those reactions into more generalized, neutral circumstances is inappropriate and can be debilitating, which would appear to occur in PTSD.

Everly $[151,152]$ also proposed that PTSD comprises a psychological sensitivity to threat and a hyperactive stress response system. According to Everly [152], the cognitive sensitivity to threat involves frontal and cingulate cortex, which activate affective and somatic stress responses in limbic structures, the sympathetic nervous system, and neuroendocrine activity in the hypothalamic-pituitaryadrenal system. Furthermore, this system comprises a positive feedback loop, such that

... affective discharge from the limbic brain sends neural impulses in two simultaneous directions: 1) to neocortical targets, and 2) to the skeletal musculature .... The neocortical centers then send impulses back to the limbic areas, thus sustaining affective arousal. At the same time, proprioceptive impulses from the skeletal musculature ascend via the reticular formation and further stimulate limbic and neocortical targets. This complex positive feedback loop serves to sustain and intensify [threat arousal] [152, p. 273].
This hyperarousal may have long-term neurological consequences; intense or protracted stimulation can produce various structural and functional changes in networks of the limbic system [152] [see also 153]. Everly [151] proposed that tonic or phasic hyperactivity of the noradrenergic system in the septo-hippocampal-amygdaloid formation explains many facets of the phenomenology of PTSD, including heightened startle responses and autonomic hyperactivity, emotional lability, irritability, fear, guilt, aggression, and intrusions such as flashbacks and nightmares. The noradrenergic system of the septo-hippocampal complex is involved in both the integration of novel or aversive stimulus information and the concomitant activation of amygdala and hypothalamic-pituitary responses to threat $[154,155]$. Also, activity in the septo-hippocampalamygdaloid network is involved in memory and panic or fear reactions [151]. Moreover, noradrenergic activation of the septohippocampal-amygdaloid system both inhibits its accommodation or habituation [151] and sensitizes it and facilitates its response to further novel or aversive stimuli $[154,155]$.

van der Kolk [50] has also discussed the role of limbic and cortical systems in traumatic cognitions. He proposed that fragmented memories in PTSD are a symptom of dysfunctional neural systems involved in the evaluation and integration of experience. Several systems are implicated, including (a) the parietal cortex in integration of multimodal sensory information, (b) the hippocampus in integration of episodic memory, (c) the cingulate as a modulator of relevant information processing (enhancing relevant and inhibiting irrelevant information), and (d) the prefrontal cortex in executive control of integrative processes [50] [see also 10].

\subsection{Hippocampal Volume in PTSD}

Recent work demonstrates abnormal hippocampal anatomy in PTSD, which has important implications for cognitive functions in PTSD [145, 153, 156-166]. Functional neuroimaging of the hippocampus demonstrates its role in novel stimulus evaluation, episodic memory, and the spatiotemporal coherence of experience [145, 153, 156-166].

Several studies have now employed high-resolution magnetic resonance imaging (MRI) to measure the volume of the hippocampus in PTSD. The studies reported an average $10 \%$ reduction in hippocampal volume, with associated deficits in short-term memory [153, 156-158, 167, 168] [cf. 169]. These studies involve careful anatomical judgment during the selection and measurement of hippocampal regions, so it is important that they involve blinded research designs [167]. The hippocampal atrophy is smaller in PTSD than amnesia. For example, Press et al. [170] reported a $49 \%$ reduction of hippocampal volume in amnesic patients (with normal parahippocampal volumes). These patients showed severe deficits of verbal and nonverbal memory, while performing normally on other tasks [170]. Nevertheless, the functional significance of the hippocampal abnormality in PTSD has prompted careful examination of this structure.

Bremner et al. [153] found an 8\% reduction of right hippocampal volume in Vietnam veterans with PTSD, which was associated with deficits in verbal short-term memory 
[see also 171]. Gurvits et al. [157] reported bilateral hippocampus reduction in combat PTSD, after controlling for age and whole brain volume. The decrease was greater in left $(26 \%)$ than right $(22 \%)$ hippocampus, especially after controlling for alcohol abuse and combat exposure. Hippocampal volume was negatively correlated with both combat exposure and PTSD symptom severity. Furthermore, hippocampal volume was positively correlated with several measures of attention and memory (digit span, arithmetic [WAIS-R], attention index [Wechsler memory scale], and delayed recall errors [Benton visual retention test]).

Several studies demonstrate smaller hippocampus in adults with a history of childhood abuse $[156,158]$. Bremner et al. [156] found a $12 \%$ smaller left hippocampal volume in adult survivors of chronic childhood abuse ( 7 to 15 years of physical, sexual or emotional abuse), with $10 \%$ of this effect solely related to PTSD diagnosis (after sex, age, education or alcohol abuse were controlled). In a similar population of women who survived childhood sex abuse, Stein et al. [158] found a $5 \%$ reduction of the left hippocampus. Bremner et al. [156] found no correlations between left hippocampal volume and verbal memory impairments (immediate and delayed recall and retention), trauma onset or duration, years since trauma cessation, or PTSD symptom severity [cf. 157]. Bremner et al. [156] propose that trauma early in life may damage hippocampal structures, but neural plasticity could recover the integrity of verbal memory processes. In this regard, they propose that some functions of the hippocampus may have shifted to the left temporal lobe, which was larger in patients [156]. However, it is also possible that larger left temporal lobes could be related to better visual performance, which might be an adaptation to a loss of verbal capacity [156].

There are some concerns that decreases in hippocampal volume in chronic PTSD may result from substance abuse or other confounds [e.g., 169, 172], and it is not clear whether smaller hippocampal volumes precede or follow a traumatic experience [171, 173]. One longitudinal study has reported no decrease in hippocampal volume between 1 week and 6 months after trauma [167]. This study had tight controls over substance abuse and it employed a blinded measurement design, whereby the persons measuring hippocampal volume were blind to both the group and time status of the data. However, this study only investigated subjects older than 20 years, after which normal development of the hippocampus and other limbic structures is complete, whereas some previous studies have investigated patients who experienced trauma during childhood or early adulthood. Nevertheless, this study identified abnormal attention and executive functions, despite a lack of clear evidence for hippocampal atrophy, suggesting that executive networks are already dysfunctional in the first 6 months of PTSD [167]. The possible conclusions are: (a) there is no hippocampal atrophy and previous findings are confounded, or (b) there is atrophy, but it may take longer than 6 months to appear, so atrophy is only apparent in chronic patients, or (c) a smaller hippocampus might predispose some people to PTSD and especially chronic PTSD [173].

With regard to (c), another study has investigated whether smaller hippocampal volume may indicate a susceptibility to PTSD. Gilbertson et al. [168] compared combat veterans with and without chronic PTSD, together with their monozygotic twins who had no combat exposure. They found $10 \%$ smaller hippocampal volume in the PTSD twin pairs and there was a significant negative relationship between hippocampal volume and the severity of PTSD in the combat veterans with PTSD $(r=-0.64)$ and their twin brothers $(r=-0.70)$. The hippocampal volume effect remained significant after controlling for whole brain volume, age, combat exposure, and noncombat trauma incidents (including childhood physical or sexual abuse). There were no significant differences in total brain volume or amygdala volume. They conclude that smaller hippocampus could be a trait indicator of the likely development of PTSD after traumatic exposure [168]. However, smaller hippocampal volume was concentrated in the severe PTSD cases. The group differences in hippocampal volume only apply to severe PTSD after combat exposure (CAPS > 65, based on a subsample of 24 from 34 combat PTSD cases). Also, the combat veterans with PTSD had a history of more alcohol abuse than any other group in the study, so the results could be confounded by alcohol abuse. Thus, this study may provide evidence that combat exposure is not a necessary condition for hippocampal atrophy, but further longitudinal studies are required to confirm this conclusion [168] [see also 174].

The findings of abnormal neuroanatomy in PTSD may be specific to hippocampal volume, rather than a general or diffuse neurological abnormality. Bremner et al. [156] noted no significant differences in several regions, including caudate and amygdala. Similarly, Gurvits et al. [157] found no differences in intracranial cavity, whole brain, ventricles, ventricle:brain ratio, or amygdala (although, the right amygdala was larger in patients than controls, which approached significance at .07). Likewise, Gilbertson et al. [168] found no differences in whole brain or amygdala volume.

However, there are two reports of extra-hippocampal abnormality in PTSD. The first study indicated focal white matter lesions in only 8 of 42 combat related PTSD patients [175]. The lesions were in periventricular regions or near the white/gray cortical junctions. The lesions were not associated with symptom severity or comorbid depression or alcohol abuse. Rauch et al. [176] conducted a more comprehensive cortical parcellation in nurses with combat exposure. Although whole cortical volume was normal, this study clearly identified smaller cortical volume in the anterior cingulate and subcallosal cortex [176]. Some near significant decreases were identified in the angular gyrus, inferior occipito-temporal gyrus and the supplementary motor cortex [176].

In summary, evidence indicates reductions of hippocampal volume in chronic PTSD, where hippocampal volume is often positively associated with deficits in attention and short-term memory, combat exposure and the severity of symptoms. Some evidence suggests that chronic childhood abuse may contribute to hippocampal atrophy, but these observations are not associated with cognitive impairment, possibly due to neural plasticity and recovery of function. One longitudinal study of trauma failed to observe hippocampal changes after 6 months. Furthermore, this study observed deficits in cognitive functions, despite no evidence 
of hippocampal atrophy. Perhaps functions that involve the hippocampus are not necessarily related to the volume of the tissue, given plasticity and the distributed networks involved in complex cognition.

\subsection{Hippocampal Physiology and Stress}

The CA3 region of the hippocampus is a central feedback target for glucocorticoids, which regulate the hypothalamicpituitaryadrenocortical (HPA) response to stress. Under stressful conditions, glucocorticoid levels increase, which is detected in the CA3 area of the hippocampus (among other locations of the HPA axis). Given this stimulus, the hippocampus can inhibit the hypothalamus from discharging corticotrophin releasing factor, thereby decreasing further cortisol responses to stress [145].

An explanation for abnormal hippocampal volume in PTSD is related to glucocorticoid physiology [e.g. 177]. Chronic, elevated levels of glucocorticoids can induce dendritic loss and cellular atrophy in the hippocampus [178182] [see also 171, 183]. Glucocorticoids can interfere with the reuptake of glutamate from the synaptic cleft, resulting in excess stimulus of post-synaptic N-methyl-D-aspartate (NMDA) receptors. This can result in an excess of intracellular calcium, which has a variety of dangerous metabolic activities. So, an excess of glutamate and NMDA activation counteracts the normal process of calcium extraction and cellular repair. This physiology is related to several explanations for hippocampal abnormality in PTSD, including (a) hippocampal dendritic pruning, (b) cellular atrophy or (c) inhibition of neurogenesis [171, 182].

However, several studies of glucocorticoid levels immediately after exposure to trauma indicate that decreased cortisol predicts development of PTSD, whereas increased cortisol predicts onset of depression [8, 183]. This evidence is inconsistent with the hippocampal atrophy hypothesis of elevated cortisol levels in PTSD. There are two ways to reconcile these findings: (a) hippocampal changes do not arise immediately after trauma, but take at least several weeks [182], or (b) there is an explanation for hippocampal atrophy that does not depend on elevated cortisol levels. This explanation refers to evidence of greater glucocorticoid receptor density and sensitivity in the HPA feedback circuits among people who develop PTSD, suggesting an abnormal sensitivity to stress and more negative feedback on the HPA endocrine response [183].

It is important to understand hippocampal pharmacology and it's relations with other cortical systems for cognition. If the hippocampal elements of the HPA feedback circuits are impaired, there should be less habituation of fear and stress responses. A possible pharmacological mechanism involves acetylcholine, which is involved in fear conditioning to context [184]. Acetylcholine is important for hippocampal theta rhythms, which are thought to synchronize distributed neural systems and facilitate the integration of sensory information into context [184]. Furthermore, there may be important interactions between acetylcholine and NMDA receptors, which are implicated in hippocampal dendritic pruning, atrophy and neurogenesis processes $[171,172,181$ 184]. Also, the involvement of NMDA and serotonin have been demonstrated by inhibition of stress induced atrophy by application of tianeptine and phenytoin $[181,185,186]$. The effects on hippocampal dendrites related to glucocorticoids and NMDA physiology can be observed after 14 days, suggesting a long-term response process [182]. Acute stress can promote a short-term increase, but a long-term depression in acetylcholine activity through modulation of gene expression [29, 187]. The impact on cognition is also important, as cholinergic systems play a role in attention, learning and memory. For example, there is evidence of greater susceptibility to distraction and novelty with decreases in hippocampal cholinergic activity [159] [cf. 145]. Similarly, neuroimaging implicates abnormal noradrenergic activity in PTSD. One PET study of an adrenergic stimulant (yohimbine) showed abnormal hippocampal activity, as well as prefrontal, orbitofrontal, parietal and temporal cortex [188]. Perhaps these cellular processes provide an explanation for the impact of trauma on contextual stimulus evaluation and learning in PTSD, which consists of generalization from one context to many contexts and failure to habituate. The physiological disturbances need not be associated with abnormal hippocampal volume [e.g. 172]; even normal levels of glucocorticoids can induce dendritic remodeling [182] [cf. 183]. The effects of stress may be related to neurotransmission adaptations and gene expression [29, 187, 189, 190] [see also 32, 148]. Nevertheless, it seems to be a disturbance of hippocampal functions that play an important role in the response to trauma in PTSD.

\section{NEUTRAL INFORMATION PROCESSING}

In contrast with studies of trauma sensitivity, studies of neutral information processing often report deficient responses in PTSD. The following sections review studies of neuropsychology, cognitive psychophysiology and cognitive neuroimaging during tasks that investigate neutral information processing, often in the absence of any traumatic information. In studies of neutral stimulus processing, it is often necessary to omit traumatic content that could provoke traumatic cognitions and affect in PTSD.

\subsection{Cognitive Neuropsychology}

As discussed above, neuropsychological theory proposes that abnormal limbic and cortical interactions contribute to difficulties with perceptual discrimination and integration of new information into episodic memory $[66,151,152,154]$ [see also 4]. Studies of PTSD demonstrate deficits of attention and executive functions [191-200] [see also 169, 193, 201, 202]. These deficits are observed in the performance of various tasks, including a continuous performance task, verbal fluency, comprehension, similarity judgments, digit-symbol substitution, and automatic tasks such as counting backwards, counting forwards by threes, and reciting the alphabet. Several studies also demonstrate memory impairments in PTSD; including immediate memory impairments in both verbal and visual tasks [191, $192,203,204]$ and some studies identify long-term memory deficits for verbal tasks and famous events [191, 204], but results for visual tasks are equivocal [192, 200, 204, 205]. Also, several studies have identified deficits of auditory verbal learning and memory [26, 192] [cf. 201]. Gurvits et al. [195] indicate that cognitive impairment may precede the onset of PTSD [cf. 201]. Gilbertson et al. [198] compare various neuropsychological measures and they argue that 
abnormal memory for neutral information is a critical determinant of PTSD diagnosis. Thus, neuropsychology studies employ trauma-neutral tasks and they most often demonstrate impairment of diverse executive cognitions in PTSD.

\subsection{Cognitive Electrophysiology}

Cognitive electrophysiology during neutral information processing provides insights into the sensory discrimination, attention and working memory processes of PTSD [see also 94]. The electrophysiological studies to date have largely focused on auditory discrimination.

Paige et al. [133] employed ERPs to investigate responses to increasing auditory intensity in PTSD. Veterans with PTSD show normal increases in N1, but abnormal decreases in P2 amplitude as auditory intensity increases toward and above the startle threshold (the effect was more prominent in the left than the right temporal area). Paige et al. [133] propose that a P2 reduction indicates "protective inhibition" -PTSD patients inhibit stimulation that could overload their capacity for accurate discrimination. Lewine [206] replicated this study with combined EEG and magneto-encephalography (MEG); they found P2 reductions in the auditory association cortex and confirm that the effect is a decrease in cortical activity rather than variation in the location of cortical source activity. These findings suggest a cortical abnormality of auditory processing in PTSD.

Recent studies suggest abnormal sensory habituation in PTSD, indicated by early auditory P50 ERPs [207-209] [see also 138]. Neylan et al. [208] reported a sophisticated investigation of P50 habituation for non-startle tones and found less habituation in PTSD patients [see also 207]. Neylan et al. [208] propose that the reduced P50 habituation could be related to deficits in hippocampal functions, which normally inhibit the response of thalamic circuits to repetitive, innocuous stimuli [many studies have implicated the hippocampus and associated limbic structures in PTSD,

[145, 153, 156-166]. These studies show that PTSD patients do not habituate the P50 response for non-startle repeated clicks, suggesting an abnormality of sensory gating in brainstem and thalamic circuits.

This evidence can be interpreted in the context of hypotheses about abnormal interactions among subcortical, limbic and cortical networks [66, 151, 152, 154]. In particular, the evidence supports the proposal that trauma leads to hyperarousal or hypersensitivity of sensory systems. If brainstem and thalamic circuits do not habituate, their cortical projections are overloaded by repetitive information. Kolb [66] proposed that excessive emotional arousal, especially threat and fear responses of the amygdala, may overload executive systems (e.g., anterior cingulate), leading to less control of subcortical and primary sensory cortical activity, with consequent deficits in cortical discrimination and adaptive response processes [210]. Primarily, thalamic nuclei become hypersensitive to any stimulus change, so their projections to the cortex can overload the capacity to process sensory information and impair corticothalamic feedback required for effective early discrimination and habituation. Furthermore, a vicious cycle of hyperarousal ensues, as the capacity of cortical processes to regulate brainstem arousal nuclei diminishes. Hence, brainstem arousal centers, such as the reticular system and the locus coeruleus, may escape from cortical control and further enhance the sensitivity of thalamic circuits and their associations with limbic and cortical networks. Thus, there could be abnormal interactions of thalamic circuits and cortical systems in PTSD, resulting in impaired neutral stimulus information processing.

This evidence complements the findings that patients have a lower threshold at which sensory discrimination is overloaded by intense stimulation, promoting cortical inhibition of excessive stimulation. The primary auditory cortex demonstrates a stimulus driven response, with N1 augmentation to increasing stimulus intensity, but the auditory association cortex demonstrates active inhibition of excessive stimulation [i.e., P2 reductions; 133, 206]. It may be only at the level of associative cortical control that the early gating deficits are counteracted [133]. Kolb [66] hypothesized that frontal cortical systems for executive control of subcortical brainstem and other thalamic circuits may be deficient. The efficient modulation of elementary sensory discrimination processes is important for adaptive stimulus information processing, so these initial insights into Kolb's [66] hypothesis form an important contribution to understanding PTSD.

An interesting study of sensory processing in the absence of attention has some important implications for any theory of early sensory processing in PTSD. Morgan and Grillon [211] investigated sensory discrimination, using an auditory mismatch negativity $(\mathrm{MMN})$ task that does not require active attention, for PTSD patients who suffered sexual assault. They found no indications of abnormal P50, N1 or P2 ERPs, but enhanced N2 amplitude, due to a larger MMN, in PTSD patients. The habituation of P50 activity is difficult to investigate and the report by Neylan et al. [208] employed sophisticated analysis procedures to clarify this issue, so their results may carry greater weight than other studies that are not specifically designed to evaluate the P50. Nevertheless, based on their evidence, Morgan and Grillon [211] conclude that the P50, N1 and P2 ERPs indicate no abnormality of auditory pathways and cortical processing in PTSD [which is consistent with studies of similar auditory discrimination tasks; see discussion below on 105, 212-216]. However, Morgan and Grillon [211] find that the enhanced MMN suggests greater activity related to auditory discrimination in PTSD [cf., 212, 215]. The MMN is thought to indicate the automatic detection of auditory stimulus changes, involving stimulus registration and comparison in sensory memory [e.g., 82, part 3]. This result suggests that previous findings of abnormal sensory discrimination in PTSD may be related to controlled attention modulations of sensory discrimination. That is, there may be abnormalities in the systems that control top-down modulation of sensory discrimination in PTSD.

These findings of Morgan and Grillon [211] should be replicated, due to concerns about comorbid panic disorder in that study. Nearly half of the PTSD sample had comorbid panic disorder (PD) with agoraphobia. It is possible that their findings of abnormal early sensory discrimination could be related to comorbid PD [217, 218]. Most studies of PD indicate abnormal activity of later, evaluation processing [219-224]. In one PTSD study, there is evidence of larger P3 
activity for PTSD patients with comorbid PD [105]. It is not yet clear if this comorbidity has implications for early ERP activity, such as the MMN.

If there is abnormal early sensory processing in PTSD, it is not clear whether cortical control processes can recover the integrity of information processing. Several ERP studies demonstrate abnormal activity during attention and working memory tasks in PTSD. In an ERP study of PTSD, McFarlane et al. [212] employed a three-tone discrimination task with common tones $(1000 \mathrm{~Hz})$ and both rare distracter $(500 \mathrm{~Hz})$ and target tones $(2000 \mathrm{~Hz}$, all stimuli had a constant duration and sub-startle intensity). For these neutral tones, PTSD patients had a slower response time and both later N2 and smaller P3 ERPs for infrequent target tones, there was also no difference of P3 amplitude for target and distracter tones. These findings were replicated several times $[213,215,225]$. The findings implicate cortical processing engaged in sensory discrimination, stimulus evaluation and working memory processes. The increase in N2 latency suggests difficulty with auditory discrimination [226] [cf. 211]. The smaller $P 3$ amplitude could reflect deficits in the evaluation of stimulus relevance or meaning [227, 228]. In a further study of the P3 evaluation process, subjects were required to detect consecutive repeats in a five tone discrimination task, which required frequent updating of the physical attributes of target tones [214]. Smaller P3 activity for common and target tones indicated deficits in working memory processing for PTSD patients $[214,215]$. This deficit was further investigated in the visual modality, which also indicated abnormal frontal and parietal ERP topography during working memory in PTSD [216, 229]. These indications of abnormal attention and working memory processes can be related to the capacity to regulate traumatic intrusions in PTSD [48]. Thus, these studies extend the findings of abnormal early sensory processing to later aspects of cortical processing engaged in stimulus discrimination, evaluation and working memory integration.

The decrease of P3 amplitude may be related to catecholamine dysfunction in PTSD. Kolb [66] hypothesized that sensory discrimination is affected by catecholamines, providing an important theoretical link between neurophysiology and cognition [see also 10,154]. There is evidence that catecholamine neurotransmission modulates the capacity for attention [230-234]. An indication that catecholamines can normalize deficits of P3 activity in PTSD was found in studies of PTSD related to combat and sexual abuse $[105,235]$. These findings indicate that catecholamine medications may normalize brain activity related to attention processes in PTSD and they provide partial support for Kolb's [66] hypothesis of catecholamine effects on cognitive processes in PTSD.

These findings of abnormal P3 in PTSD can be modified by symptom severity and comorbidity. There are decreases in P3 and slower reaction times with dissociative and numbing symptoms [103, 104], as well as depression symptoms [105]. There are increases in P3 with panic symptoms $[105,219,235]$. Furthermore, the abnormality in P3 processes is not specific to PTSD [236], it has been observed in diverse psychiatric conditions, which suggests a central role for these processes in integrated cognition.
The neutral stimulus processing in PTSD could vary with affective states. That is, attention bias theory would predict that during stressful or traumatic affect, the attention available for neutral stimuli decreases. However, Kaufman [103] found no effects of emotional state on P3 responses to neutral stimuli. Previous work has either included emotive or trauma content into task materials or ensured that all task materials and the emotional context are neutral [102]. Kaufman [103] employed a neutral auditory discrimination task with prior induction of an affective context. Across three affective contexts, neutral, stressful and traumatic, there were no modulations of the P3 effects for neutral auditory processing. However, the emotional context did have an impact on dissociative states, which were related to P3 effects for distracters $[102,103]$. This study suggests that attention biases are not simply a result of general affective states, but rather they arise as specific responses to stimulus information.

The distraction in PTSD could be dependent on the novelty of the information, because several studies demonstrate larger P3 activity for novel stimuli in PTSD. Blomhoff et al. [102] found larger frontal activity at 200-300 msec for rare, novel acoustic non-words in PTSD, which is very similar to P3a effects that indicate an orientation of attention to novel stimuli. They also found that this frontal activity between $150-300 \mathrm{msec}$ was positively associated with the arousal, avoidance and intrusion symptoms of PTSD. Similarly, Kimble et al. [237] investigated novelty sensitivity in combat veterans with or without PTSD. They used two auditory tasks. One was a three-tone oddball task, with $1000 \mathrm{~Hz}$ common tones, $500 \mathrm{~Hz}$ rare distracters and $2000 \mathrm{~Hz}$ rare target tones. The second task was almost identical, except the $500 \mathrm{~Hz}$ rare distracters were replaced with various novel sounds (clicks, buzzes, etc.). If PTSD patients are susceptible to novel distraction, they expected to see larger ERP activity for the novel stimuli. Also, they expected to see greater impairment of target processing in the novel task. In fact, their results show that all subjects did have smaller P3 activity for targets during the novelty task, indicating that novel stimuli diverted attention from the primary task. However, there were no group differences in this deficit for target processing ${ }^{2}$. There was a group by task interaction for distracters, which comprised greater frontal P3 amplitude for novel than pure tone distracters in PTSD. The effect identified was significant after adjustment for combat exposure and comorbid panic disorder (there was no correction for depression). This finding required comparisons between neutral and novel, ambiguous distracters. With similar task designs, it is possible to explore the effects of emotional distracters [c.f., 102, 238]. The novel sounds in these studies were not related to traumatic experience and therefore suggest that threat sensitivity in PTSD extends beyond traumatic stimuli to any ambiguous novel stimuli.

\subsection{Cognitive Neuroimaging}

Semple et al. [239, 240] found abnormal activity in parietal attention systems during neutral information processing in PTSD [see also 241]. They investigated rCBF

\footnotetext{
${ }^{2}$ This is inconsistent with findings from very similar auditory discrimination
} tasks [105, 212, 213, 225, 235]. 
in combat PTSD during an auditory continuous performance task (CPT), which required vigilant attention and discrimination for rare target events. PTSD patients had poor discrimination of targets and decreased $\mathrm{rCBF}$ in the angular gyrus of the right parietal cortex, a brain region that is implicated in multimodal attention processes [239, 240, 242, 243]. The parietal $\mathrm{rCBF}$ was positively associated with performance accuracy $[239,240]$. Although the patient group had a comorbid substance abuse, the authors suggest their results are due to PTSD, because patients abstained for several weeks before the study and the PTSD results were inconsistent with results from another substance abuse group $[239,240]$.

Several recent papers demonstrate abnormal functional activity in PTSD for neutral stimuli [244-246]. Clark et al. [245] employed PET during two target detection tasks, using the same visual stimuli, with two different task instructions. In one task, a target word remained constant, while the other task required detection of repeated words (a variable target). The latter task required greater verbal working memory updating, as each non-target word became a new target template. In controls, activation was identified in a working memory network, including the dorsolateral prefrontal cortex, the orbitofrontal cortex and anterior cingulate, as well as the supramarginal gyrus of the inferior parietal lobe [246]. PTSD patients demonstrated less prefrontal activity, especially in the left dorsolateral prefrontal cortex, with possible compensation apparent in greater activity in the right parietal cortex [229, 244, 245]. This pattern of activity was taken to indicate deficits in prefrontal control of working memory content, which may be stored as multimodal representations in posterior parietal regions. The deficit in left prefrontal activity may be associated with decreased verbal skills in PTSD, which has been observed in studies of traumatic information processing [114]. In contrast with those studies of traumatic imagery, activation was identified in the middle frontal gyrus, which is implicated in speech production and more complex integration of information in working memory [247-250]. Thus, this work demonstrates a more fundamental difficulty with working memory for neutral information in PTSD, which is consistent with theories about the dissociation of traumatic memory from linguistic, narrative encoding [50]. Also, the integrity of working memory processes can be related to the capacity to control intrusive memories [48].

\subsection{Psychophysiology}

PTSD patients have high cardiovascular activity, including increased heart rates and diastolic and systolic blood pressure, during resting periods of laboratory research $[128,140]$, and before a routine outpatients physical examination [251]. Casada [141] found that PTSD patients have higher baseline electrodermal activity, but not heart rate, in comparison with combat and non-combat controls. Furthermore, PTSD patients have often demonstrated a heightened startle response to sudden loud tones, which is indicated by increased eye blink amplitude, heart rate, skin conductivity, and diminished habituation of skin conductivity over several tone presentations $[132,133,135$, 136]. An exception to these findings is that PTSD patients show no significant startle response to $2 \mathrm{sec}$ of white noise presented at $80 \mathrm{~dB}$ [129]. PTSD patients may be less responsive to the white noise, which had a longer duration and a different sound texture, than the sudden tones presented in other studies.

The physiological hyperactivity in PTSD, while among neutral circumstances, cannot be explained as a conditioned response. Shalev et al. $[135,136]$ proposed that hyperarousal symptoms indicate a genetic disposition or an acquired sensitivity to autonomic reactivity and a diminished habituation of autonomic responses. Gerardi [251] proposed that PTSD patients may activate a cognitive fear network during any laboratory or hospital visit and this promotes physiological arousal.

\subsection{Summary}

Psychophysiology studies indicate hyperarousal in PTSD, even among relatively neutral circumstances. At the cognitive level, neuropsychology studies indicate deficits in various attention and memory tasks. Several ERP studies demonstrate abnormal thalamic gating and early sensory processing for auditory tones in PTSD. There is also evidence for abnormal stimulus discrimination, evaluation and working memory integration, indicated by abnormal N2 and P3 ERPs in PTSD. Finally, several studies of rCBF demonstrate abnormal activity in frontal and parietal systems engaged in attention and working memory processes.

\section{CONCLUSIONS}

A traumatic experience can promote development of a trauma schema, consisting of sensory, affective, and intentional information that may be dissociated from linguistic, symbolic representation. This trauma schema not only facilitates assimilation of traumatic information, but also encourages appraisal of novel or ambiguous events as threats to well-being. Cognitive and electrophysiological studies have demonstrated heightened sensitivity for traumatic and possibly novel stimuli in PTSD. Of particular interest are the ERP studies that show early, automatic attention to traumatic stimuli and greater conscious attention to the significance or meaning of traumatic images. Also, neuroimaging indicates greater activation in the limbic system during traumatic recollection, especially the amygdala, with associated abnormalities in the appraisal systems of the orbitofrontal and anterior cingulate regions. This work also demonstrates that traumatic recollection is associated with diminished activity in left inferior frontal cortex, which suggests that traumatic memories consist of sensory and emotional elements without concomitant linguistic associations. Many cohort studies demonstrate an association between trauma sensitivity and the severity of PTSD symptoms, especially traumatic intrusions. Longitudinal studies of the association between cognition and symptom development may clarify whether any sensitivity to threat and trauma content precedes or follows traumatic experience. The PTSD symptom profile may be evaluated with regard to the interactions of cognitive and affective processes with peripheral physiology. It is important to study the integration of central neural systems with the peripheral physiology. Many studies investigate one or another of these aspects, yet this will not clarify the causal relations between cognitive and affective appraisals and peripheral physiological concomitants, including abnormal 
neuroendocrine and autonomic regulation, which are important feedback indicators to central processes. For this reason, desensitization of peripheral autonomic responses to traumatic cognitions may play an important role in recovery from PTSD.

A bias toward traumatic cognitions may interfere with adaptive cognitive structures for processing neutral information. There is no conclusive evidence of deficits in neutral information processing in the concurrent presence of traumatic information, only that traumatic stimulation decreases the ability to discriminate relevant neutral information from traumatic distractions. However, there is considerable evidence of abnormal neutral information processing in PTSD, in the absence of traumatic information. There is support for the neuropsychological theory of Kolb [66] in the ERP research that demonstrates greater protective inhibition in PTSD (suggesting the threshold at which accurate discrimination occurs is lower in PTSD, promoting earlier inhibition of excessive stimulation). Further ERP research has also demonstrated a difficulty in the conscious evaluation of the significance or relevance of neutral information. This latter difficulty has also been related to abnormal rCBF in several areas of a cortical network engaged in attention and working memory processes. There is also evidence of susceptibility to novel distraction in PTSD, which could be related to abnormal hippocampal, parahippocampal and prefrontal attention systems engaged in contextual novelty processing.

\section{REFERENCES}

[1] Buckley TC, Blanchard EB, Neill WT. Information processing and PTSD: a review of the empirical literature. Clin Psychol Rev 2000; 20(8): 1041-1065. Available from: http://dx.doi.org/10.1016/S0272-7358(99) 00030-6.

[2] Ehlers A, Clark DM. A cognitive model of posttraumatic stress disorder. Behav Res Ther 2000; 38(4): 319-345.

[3] Villarreal G, King CY. Brain imaging in posttraumatic stress disorder. Semin Clin Neuropsychiatry 2001; 6(2): 131-145.

[4] Brewin CR. A cognitive neuroscience account of post-traumatic stress disorder and its treatment. Behav Res Ther 2001; 39(4): 373 393.

[5] Brewin CR, Holmes EA. Psychological theories of post-traumatic stress disorder. Clin Psychol Rev 2003; 23(3): 339-376.

[6] Bonne O, Grillon C, Vythilingam M, Neumeister A, Charney DS. Adaptive and maladaptive psychobiological responses to severe psychological stress: implications for the discovery of novel pharmacotherapy. Neurosci Biobehav Rev 2004; 28(1): 65-94. Available from: http://dx.doi.org/10.1016/j.neubiorev.2003.12.001.

[7] Weber DA, Reynolds CR. Clinical perspectives on neurobiological effects of psychological trauma. Neuropsychol Rev 2004; 14(2): 115-129. Available from: http: //dx.doi.org/10.1023/B:NERV.0000028082.13778.14.

[8] McFarlane AC. The prevalence and longitudinal course of PTSD: Implications for the neurobiological models of PTSD. Ann N Y Acad Sci 1997; 821: 10-23.
[9] Tryon WW. A neural network explanation of posttraumatic stress disorder. J Anxiety Disord 1998; 12(4): 373-385. Available from: http://dx.doi.org/10.1016/ S0887-6185(98)00021-8.

[10] McFarlane AC, Yehuda R, Clark CR. Biologic models of traumatic memories and post-traumatic stress disorder: The role of neural networks. Psychiatr Clin North Am 2002; 25: 253-270. Available from: http://dx.doi.org/ 10.1016/S0193-953X(01)00008-9.

[11] American Psychiatric Association. Diagnostic and Statistical Manual of Mental Disorders. 4th ed. Washington DC: American Psychiatric Association Press; 1994.

[12] Warshaw M, Fierman E, Pratt L, Hunt M, Yonkers K, Massion A, et al. Quality of life and dissociation in anxiety disorder patients with histories of trauma or PTSD. Am J Psychiatry 1993; 150: $1512-1516$.

[13] Yehuda R, McFarlane AC. Conflict between current knowledge about posttraumatic stress disorder and its original conceptual basis. Am J Psychiatry 1995; 152: 1705-1713.

[14] Brewin CR, Andrews B, Rose S. Diagnostic overlap between acute stress disorder and PTSD in victims of violent crime. Am J Psychiatry 2003; 160(4): 783-785.

[15] Kulka R. Trauma and the Vietnam War Generation: Report of Findings from the National Vietnam Veterans Readjustment Study. New York: Brunner/Mazel; 1990.

[16] Green B. Psychosocial research in traumatic stress: An update. J Trauma Stress 1994; 7: 341-360.

[17] O’Donnell M, Creamer M, Bryant RA, Schnyder U, Shalev A. Posttraumatic disorders following injury: an empirical and methodological review. Clin Psychol Rev 2003; 23: 587-603.

[18] Foa E. Psychological processes related to recovery from a trauma and an effective treatment for PTSD. Ann N Y Acad Sci 1997; 821: $410-424$.

[19] Bryant RA. Early predictors of posttraumatic stress disorder. Biol Psychiatry 2003; 53: 789-795.

[20] Schnurr P, Friedman M, Rosenberg S. Premilitary MMPI scores as predictors of combat-related PTSD symptoms. Am J Psychiatry 1993; 150: 479-483.

[21] Goenjian A, Najarian L, Pynoos R, Steinberg A, Manoukian G, Tavosian A, et al. Posttraumatic stress disorder in elderly and younger adults after the 1988 earthquake in Armenia. Am J Psychiatry 1994; 151: 895-901.

[22] Koopman C, Classen C, Spiegel D. Predictors of post-traumatic stress symptoms among survivors of the Oakland/Berkeley, California, firestorm. Am J Psychiatry 1994; 151: 888-894.

[23] McCarroll J, Ursano R, Fullerton C. Symptoms of PTSD following recovery of war dead: 13-15 month follow-up. Am J Psychiatry 1995; 152: 939-941.

[24] McNally R, Shin L. Association of intelligence with severity of posttraumatic stress disorder symptoms in Vietnam combat veterans. Am J Psychiatry 1995; 152: 936-938.

[25] Weine S, Becker D, McGlashan T, Laub D, Lazrove S, Vojvoda D, et al. Psychiatric consequences of "ethnic cleansing": Clinical 
assessments and trauma testimonies of newly resettled Bosnian refugees. Am J Psychiatry 1995; 152: 536-542.

[26] Yehuda R, Kahana B, Schmeidler J, Southwick S, Wilson S, Giller E. Impact of cumulative lifetime trauma and recent stress on current posttraumatic stress disorder symptoms in holocaust survivors. Am J Psychiatry 1995; 152: 1815-1818.

[27] Seedat S, Niehaus D, Stein D. The role of genes and family in trauma exposure and posttraumatic stress disorder. Mol Psychiatry 2001; 6: 360-362.

[28] Creamer M, Burgess P, Pattison P. Reaction to trauma: a cognitive processing model. J Abnorm Psychol 1992; 101(3): 452-459.

[29] Kaufer D, Friedman A, Seidman S, Soreq H. Acute stress facilitates long-lasting changes in cholinergic gene expression. Nature 1998; 393(6683): 373-377. Available from: http://dx.doi.org/10.1038/30741.

[30] Halligan SL, Clark DM, Ehlers A. Cognitive processing, memory, and the development of PTSD symptoms: two experimental analogue studies. J Behav Ther Exp Psychiatry 2002; 33(2): 73-89.

[31] Delahanty D, Raimonde A, Spoonster E, Cullado M. Injury severity, prior trauma history, urinary cortisol levels, and acute PTSD in motor vehicle accident victims. J Anxiety Disord 2003; 17: $149-164$

[32] Vaiva G, Ducrocq F, Jezequel K, Averland B, Lestavel P, Brunet $\mathrm{A}$, et al. Immediate treatment with propranolol decreases posttraumatic stress disorder two months after trauma. Biol Psychiatry 2003; 54: 947-949.

[33] Horowitz M. Stress Response Syndromes. 2nd ed. New York: Jason Aronson; 1986.

[34] Festinger L. A Theory of Cognitive Dissonance. Stanford CA: Stanford University Press; 1957.

[35] Brett E, Ostroff R. Imagery and posttraumatic stress disorder: an overview. Am J Psychiatry 1985; 142(4): 417-

424. Available from: http://ajp.psychiatryonline.org/cgi/ content/abstract/142/4/417.

[36] Weiner B. An Attributional Theory of Motivation and Emotion. New York: Springer-Verlag; 1986.

[37] Bandura A. Self-efficacy: toward a unifying theory of behavioral change. Psychol Rev 1977; 84(2): 191-215.

[38] Bandura A, Caprara GV, Barbaranelli C, Gerbino M, Pastorelli C. Role of affective self-regulatory efficacy in diverse spheres of psychosocial functioning. Child Dev 2003; 74(3): 769-782.

[39] Seligman M, Abramson L, Semmel A, von Baeyer C. Depressive attributional style. J Abnorm Psychol 1979; 88: 242-247.

[40] Seligman M. Authentic Happiness: Using the New Positive Psychology to Realize Your Potential for Lasting Fulfillment. New York: Free Press/Simon and Schuster; 2002.

[41] Roesch SC, Weiner B, Vaughn AA. Cognitive approaches to stress and coping. Curr Opin Psychiatry 2002; 15(6): 627-632. Available from: http://www.co-psychiatry.com/pt/re/copsych/abstract. 00001504-200211000-00012.htm.
[42] Mikulincer M, Solomon Z. Attributional style and combat-related posttraumatic stress disorder. J Abnorm Psychol 1988; 97: 308313.

[43] Southwick SM, Yehuda R, Giller EL. Characterization of depression in war-related posttraumatic stress disorder. Am J Psychiatry 1991; 148(2): 179-183.

[44] Yehuda R, Kahana B, Southwick SM, Giller EL. Depressive features in Holocaust survivors with post-traumatic stress disorder. J Trauma Stress 1994; 7(4): 699-704.

[45] Saigh PA, Mroueh M, Zimmerman BJ, Fairbank JA. Self-efficacy expectations among traumatized adolescents. Behav Res Ther 1995; 33(6): 701-704. Available from: http://dx.doi.org/10.1016/0005-7967(94) 00092-X.

[46] Nezu AM, Carnevale GJ. Interpersonal problem solving and coping reactions of Vietnam veterans with posttraumatic stress disorder. J Abnorm Psychol 1987; 96(2): 155-157.

[47] Solomon Z, Bleich A, Shoham S, Nardi C, Kotler M. The 'Koach' project for treatment of combat-related PTSD: Rationale, aims, and methodology. J Trauma Stress 1992; 5(2): 175-193. Available from: $\quad$ http://www.springerlink.com/openurl.asp?genre= article\&id=doi:10.1007/BF00976708.

[48] Brewin CR, Smart L. Working memory capacity and suppression of intrusive thoughts. J Behav Ther Exp Psychiatry 2005; 36(1): 61-68. Available from: http: //dx.doi.org/10.1016/j.jbtep.2004.11.006.

[49] van der Kolk B, Herron N, Hostetler A. The history of trauma in psychiatry. Psychiatr Clin North Am 1994; 17: 583-600.

[50] van der Kolk B. The psychobiology of traumatic memory: Clinical implications of neuroimaging studies. Ann N Y Acad Sci 1997; 821: 99-113

[51] Leys R. Trauma: A Genealogy. London: The University of Chicago Press; 2000.

[52] Schank RC, Abelson R. Scripts, Plans, Goals, and Understanding: An Inquiry into Human Knowledge Structures. Hillsdale, NJ: Lawrence Erlbaum Associates; 1977.

[53] Schank RC. Dynamic Memory: A Theory of Reminding and Learning in Computers and People. Cambridge: Cambridge University Press; 1982

[54] Schank RC. Explanation Patterns: Understanding Mechanically and Creatively. Hillsdale, NJ: Lawrence Erlbaum Associates; 1986.

[55] Schank RC. Dynamic Memory Revisted. Cambridge: Cambridge University Press; 1999.

[56] Mandler J. Stories, Scripts, and Scenes: Aspects of Schema Theory Hillsdale NJ: Erlbaum; 1984.

[57] Lang PJ. Presidential address, 1978. A bio-informational theory of emotional imagery. Psychophysiology 1979; 16(6): 495-512.

[58] Chemtob C, Roitblat H, Hamada R, Carlson J, Twenty-man C. A cognitive action theory of post-traumatic stress disorder. J Anxiety Disord 1988; 2: 253-275. 
[59] Foa E, Steketee G, Olasov-Rothbaum B. Behavioral/Cognitive conceptualisations of post-traumatic stress disorder. Behav Ther 1989; 20: 155-176.

[60] Litz B, Keane T. Information processing in anxiety disorders: application to the understanding of post-traumatic stress disorder. Clin Psychol Rev 1989; 9: 243-257.

[61] Michael T, Halligan SL, Clark DM, Ehlers A. Rumination in posttraumatic stress disorder. Depress Anxiety 2007; 24(5): $307-$ 317. Available from: http://dx.doi. org/10.1002/da.20228.

[62] Halligan SL, Michael T, Clark DM, Ehlers A. Posttraumatic stress disorder following assault: the role of cognitive processing, trauma memory, and appraisals. J Consult Clin Psychol 2003; 71(3): 419431.

[63] Riskind JH. Looming vulnerability to threat: a cognitive paradigm for anxiety. Behav Res Ther 1997; 35(8): 685-702.

[64] Goldman-Rakic P. Topography of cognition: Parallel distributed networks in primate association cortex. Annu Rev Neurosci 1988; 11: $137-156$.

[65] Treisman A. The binding problem. Curr Opin Neurobiol 1996; 6: 171-178.

[66] Kolb LC. A neuropsychological hypothesis explaining posttraumatic stress disorders. Am J Psychiatry 1987; 144(8): 989995. Available from: http:/ajp. psychiatryonline.org/cgi/content/abstract/144/8/989.

[67] Trandel D, McNally R. Perception of threat cues in post-traumatic stress disorder: semantic processing without awareness? Behav Res Ther 1987; 25: 469-476.

[68] Cohen JD, Dunbar K, McClelland JL. On the control of automatic processes: A parallel distributed processing account of the Stroop effect. Psychol Rev 1990; 97(3): 332-361.

[69] Williams JM, Mathews A, MacLeod C. The emotional Stroop task and psychopathology. Psychol Bull 1996; 120(1): 3-24.

[70] Cassiday K, McNally R, Zeitlin S. Cognitive processing of trauma cues in rape victims with post-traumatic stress disorder. Cognit Ther Res 1992; 16: 283-295.

[71] McNally R, Kaspi S, Riemann B, Zeitlin S. Selective processing of threat cues in posttraumatic stress disorder. J Abnorm Psychol 1990; 99: 398-402.

[72] Foa E, Feske U, Murdock T, Kozak M, McCarthy P. Processing of threat-related information in rape victims. J Abnorm Psychol 1991; 100: $156-162$.

[73] Thrasher S, Dalgleish T, Yule W. Information processing in posttraumatic stress disorder. Behav Res Ther 1994; 32: 247-254.

[74] Bryant RA, Harvey AG. Processing threatening information in posttraumatic stress disorder. J Abnorm Psychol 1995; 104(3): 537541.

[75] Zeitlin S, McNally R. Implicit and explicit memory bias for threat in post-traumatic stress disorder. Behav Res Ther 1991; 29: 451457.
[76] McNally R, Litz B, Prassas A, Shin L, Weathers F. Emotional priming of autobiographical memory in post-traumatic stress disorder. Cognition and Emotion 1994; 8: 351-367.

[77] McNally R, Lasko N, Macklin M, Pitman R. Autobiographical memory disturbance in combat-related post-traumatic stress disorder. Behav Res Ther 1995; 33: 619-630.

[78] McNally R. Implicit and explicit memory for trauma-related information in PTSD. Ann N Y Acad Sci 1997; 821: 219-224.

[79] Michael T, Ehlers A, Halligan SL. Enhanced priming for traumarelated material in posttraumatic stress disorder. Emotion 2005; 5(1): 103-112. Available from: http: //dx.doi.org/10.1037/15283542.5.1.103.

[80] Kutas M, Hillyard S. Event-related potentials in cognitive science. In: Gazzaniga M, editor. Handbook of Cognitive Neuroscience. New York: Plenum Press; 1984. p. 387-409.

[81] Regan D. Human Brain Electrophysiology. New York: Elsevier; 1989.

[82] Näätänen R. The role of attention in auditory information processing as revealed by event-related potentials and other brain measures of cognitive function. Behav Brain Sci 1990; 13: 201288.

[83] Hillyard SA, Woldorff M, Mangun GR, Hansen JC. Mechanisms of early selective attention in auditory and visual modalities. Electroencephalogr Clin Neurophysiol Suppl 1987; 39: 317-324.

[84] Woldorff M, Hansen JC, Hillyard SA. Evidence for effects of selective attention in the mid-latency range of the human auditory event-related potential. Electroencephalogr Clin Neurophysiol Suppl 1987; 40: 146-154.

[85] Woldorff MG, Gallen CC, Hampson SA, Hillyard SA, Pantev C, Sobel $\mathrm{D}$, et al. Modulation of early sensory processing in human auditory cortex during auditory selective attention. Proc Natl Acad Sci USA 1993; 90(18): 8722-8726.

[86] Kastner S, De Weerd P, Desimone R, Ungerleider LG. Mechanisms of directed attention in the human extrastriate cortex as revealed by functional MRI. Science 1998; 282(5386): 108-111.

[87] Kastner S, Pinsk MA, De Weerd P, Desimone R, Ungerleider LG. Increased activity in human visual cortex during directed attention in the absence of visual stimulation. Neuron 1999; 22(4): 751-761.

[88] Martínez A, DiRusso F, Anllo-Vento L, Sereno MI, Buxton RB, Hillyard SA. Putting spatial attention on the map: timing and localization of stimulus selection processes in striate and extrastriate visual areas. Vision Res 2001; 41(10-11): 1437-1457. Available from: http://dx.doi.org/10.1016/S0042-6989(00)00267-4.

[89] Kastner S, O'Connor DH, Fukui MM, Fehd HM, Herwig U, Pinsk MA. Functional imaging of the human lateral geniculate nucleus and pulvinar. J Neurophysiol 2004; 91(1): 438-448.

[90] Busse L, Roberts KC, Crist RE, Weissman DH, Woldorff MG. The spread of attention across modalities and space in a multisensory object. Proc Natl Acad Sci USA 2005; 102(51): 18751-18756. Available from: http://dx.doi. org/10.1073/pnas.0507704102. 
[91] Talsma D, Woldorff MG. Selective attention and multisensory integration: multiple phases of effects on the evoked brain activity. J Cogn Neurosci 2005; 17(7): 1098-1114. Available from: http://dx.doi.org/10.1162/ 0898929054475172.

[92] Ahveninen J, Jääskeläinen IP, Raij T, Bonmassar G, Devore S, Hämäläinen $\mathrm{M}$, et al. Task-modulated "what" and "where" pathways in human auditory cortex. Proc Natl Acad Sci USA 2006; 103(39): 14608- $14613 . \quad$ Available from: http://dx.doi.org/10.1073/pnas. 0510480103.

[93] Jääskeläinen IP, Ahveninen J, Belliveau JW, Raij T, Sams M. Short-term plasticity in auditory cognition. Trends Neurosci 2007; 30(12): 653-661. Available from: http://dx.doi.org/10.1016/j.tins.2007.09.003.

[94] Karl A, Malta LS, Maercker A. Meta-analytic review of eventrelated potential studies in post-traumatic stress disorder. Biol Psychol 2006; 71(2): 123-147. Available from: http://dx.doi.org/10.1016/j.biopsycho.2005.03.004.

[95] Attias J, Bleich A, Gilat S. Classification of veterans with posttraumatic stress disorder using visual brain evoked $\mathrm{P} 3 \mathrm{~s}$ to traumatic stimuli. Br J Psychiatry 1996; 168: 110-115.

[96] Attias J, Bleich A, Furman V, Zinger Y. Event-related potentials in post-traumatic stress disorder of combat origin. Biol Psychiatry 1996; 40: 373-381.

[97] Bleich AV, Attias J, Furman V. Effect of repeated visual traumatic stimuli on the event related $\mathrm{P} 3$ brain potential in post-traumatic stress disorder. Int J Neurosci 1996; 85(1-2): 45-55.

[98] Kounios J, Litz B, Kaloupek D, Riggs D, Knight J, Weathers F, et al. Electrophysiology of combat-related PTSD. Ann N Y Acad Sci 1997; 821: 504-507.

[99] Stanford MS, Vasterling JJ, Mathias CW, Constans JI, Houston RJ. Impact of threat relevance on P300 event-related potentials in combat-related posttraumatic stress disorder. Psychiatry Res 2001; 102: $125-137$

[100] Shiffer F, Teicher M, Papanicolaou A. Evoked potential evidence for right brain activity during the recall of traumatic memories. J Neuropsychiatry Clin Neurosci 1995; 7: 169-175.

[101] Metzger L, Orr S, Lasko N, McNally R, Pitman R. Seeking the source of the emotional Stroop interference effects in PTSD: a study of P3s to traumatic words. Integr Physiol Behav Sci 1997; 32: 43-51.

[102] Blomhoff S, Reinvang I, Malt U. Event-related potentials to stimuli with emotional impact in posttraumatic stress patients. Biol Psychiatry 1998; 44: 1045-1053. Available from: http://dx.doi.org/10.1016/ S0006-3223(98)00058-4.

[103] Kaufman M. Dissociation status and attentional allocation in male Vietnam combat veterans with post-traumatic stress disorder [Digital Dissertations, AAT 3040708]. Boston University; 2002.

[104] Felmingham KL, Bryant RA, Kendall C, Gordon E. Event-related potential dysfunction in posttraumatic stress disorder: the role of numbing. Psychiatry Res 2002; 109: 171-179.
[105] Metzger L, Orr S, Lasko N, Pitman R. Auditory event-related potentials to tone stimuli in combat-related post-traumatic stress disorder. Biol Psychiatry 1997; 42: 1006-1015.

[106] Gangadhar BN, Ancy J, Janakiramaiah N, Umapathy C. P300 amplitude in non-bipolar, melancholic depression. J Affect Disord 1993; 28(1): 57-60.

[107] Santosh PJ, Malhotra S, Raghunathan M, Mehra YN. A study of P300 in melancholic depression-correlation with psychotic features. Biol Psychiatry 1994; 35(7): 474-479.

[108] Ancy J, Gangadhar BN, Janakiramaiah N. Normal P300 amplitude predicts rapid response to ECT in melancholia. J Affect Disord 1996; 41(3): 211-215.

[109] Yanai I, Fujikawa T, Osada M, Yamawaki S, Touhouda Y. Changes in auditory P300 in patients with major depression and silent cerebral infarction. J Affect Disord 1997; 46(3): 263-271. Available from: http://dx.doi. org/10.1016/S0165-0327(97)001006.

[110] Vandoolaeghe E, van Hunsel F, Nuyten D, Maes M. Auditory event related potentials in major depression: prolonged P300 latency and increased P200 amplitude. J Affect Disord 1998; 48(23): 105-113. Available from: http://dx.doi.org/10.1016/S01650327(97)00165-1.

[111] Patterson JV, Michalewski HJ, Starr A. Latency variability of the components of auditory event-related potentials to infrequent stimuli in aging, Alzheimer-type dementia, and depression. Electroencephalogr Clin Neurophysiol 1988; 71(6): 450-460.

[112] Sara G, Gordon E, Kraiuhin C, Coyle S, Howson A, Meares R. The P300 ERP component: An index of cognitive dysfunction in depression? J Affect Disord 1994; 31(1): 29-38.

[113] Felmingham KL, Bryant RA, Gordon E. Processing angry and neutral faces in post-traumatic stress disorder: an event-related potentials study. Neuroreport 2003; 14(5): 777-780.

[114] Rauch S, van der Kolk B, Fisler R, Alpert N, Orr S, Savage C, et al. A symptom provocation study of post-traumatic stress disorder using positron emission tomography and script-driven imagery. Arch Gen Psychiatry 1996; 53: 380-387.

[115] Shin L, Kosslyn S, McNally R, Alpert N, Thompson W, Rauch S, et al. Visual imagery and perception in posttraumatic stress disorder: A positron emission tomographic investigation. Arch Gen Psychiatry 1997; 54: 233-241.

[116] Ehlers CL, Hurst S, Phillips E, Gilder DA, Dixon M, Gross A, et al. Electrophysiological responses to affective stimuli in American Indians experiencing trauma with and without PTSD. Ann N Y Acad Sci 2006; 1071: 125-136. Available from: http://dx.doi.org/10. 1196/annals.1364.011.

[117] Shin LM, McNally RJ, Kosslyn SM, Thompson WL, Rauch SL, Alpert NM, et al. Regional cerebral blood flow during script-driven imagery in childhood sexual abuse-related posttraumatic stress disorder: A positron emission tomographic investigation. Am J Psychiatry 1999; 156: 575-584.

[118] Rauch S, Shin L. Functional neuroimaging studies in posttraumatic stress disorder. Ann N Y Acad Sci 1997; 821: 83-98. 
[119] Rauch S, Savage C, Alpert N, Fischman A, Jenike M. The functional neuroanatomy of anxiety: A study of three disorders using positron emission tomography and symptom provocation. Biol Psychiatry 1997; 42: 446-

452.

[120] Damasio A, Tranel D, Damasio H. Somatic markers and the guidance of behavior: Theory and preliminary testing. In: Levin $\mathrm{H}$, Eisenberg H, Benton A, editors. Frontal Lobe Function and Dysfunction. New York: Oxford University Press; 1991. p. 217229.

[121] Botvinick MM, Cohen JD, Carter CS. Conflict monitoring and anterior cingulate cortex: an update. Trends Cogn Sci 2004; 8(12): $539-546$.

[122] LeDoux J. Information flow from sensation to emotion: Plasticity in the neural computation of stimulus value. In: Gabriel M, Moore J, editors. Learning and Computational Neuroscience: Foundations of Adaptive Networks. Cambridge, Massachusetts: MIT Press; 1990. p. 3-51.

[123] LeDoux J. In search of an emotional system in the brain: Leaping from fear to emotion and consciousness. In: Gazzaniga MS, editor. The Cognitive Neurosciences. Cambridge, Massachusetts: MIT Press; 1995. p. 1049- 1061.

[124] Fig L, Liberzon I, Steventon R, Minoshima S, Koeppe R. Regional cerebral blood flow SPECT in post-traumatic stress disorder: Results of SPECT activation study. The Journal of Nuclear Medicine 1995; 36, Proceedings of 42nd Annual Meeting:Abstract 345 .

[125] Schiffer F, Teicher MH, Papanicolaou AC. Evoked potential evidence for right brain activity during the recall of traumatic memories. J Neuropsychiatry Clin Neurosci 1995; 7(2): 169-175.

[126] Rauch S, Whalen P, Shin L, McInerney S, Macklin M, Lasko N, et al. Exaggerated amygdala response to masked facial stimuli in posttraumatic stress disorder: A functional MRI study. Biol Psychiatry 2000; 47: 769-776.

[127] Blanchard E, Kolb L, Pallmeyer T, Gerardi R. A psychophysiological study of post traumatic stress disorder in Vietnam veterans. Psychiatr Q 1982; 54: 220-229.

[128] Blanchard E, Kolb L, Gerardi R, Ryan P, Pallmeyer T. Cardiac response to relevant stimuli as an adjunctive tool for diagnosing post-traumatic stress disorder in Vietnam veterans. Behav Ther 1986; 17: 592-606.

[129] Pallmeyer T, Blanchard E, Kolb L. The psychophysiology of combat-induced post-traumatic stress disorder in Vietnam veterans. Behav Res Ther 1986; 24: 645-652.

[130] Pitman R, Orr S, Forgue D, de Jong J, Claiborn J. Psychophysiologic assessment of posttraumatic stress disorder imagery in Vietnam combat veterans. Arch Gen Psychiatry 1987; 44: 970-975.

[131] Gerardi R, Keane TM, Penk W. Utility: Sensitivity and specificity in developing diagnostic tests of combat-related post-traumatic stress disorder (PTSD). J Clin Psychol 1989; 45(5): 691-703.
[132] Butler RW, Braff DL, Rausch JL, Jenkins MA, Sprock J, Geyer MA. Physiological evidence of exaggerated startle response in a subgroup of Vietnam veterans with combat-related PTSD. Am J Psychiatry 1990; 147(10): 1308-1312.

[133] Paige S, Reid G, Allen M, Newton J. Psychophysiological correlates of posttraumatic stress disorder in Vietnam veterans. Biol Psychiatry 1990; 27: 419-430.

[134] Blanchard E, Kolb L, Prins A. Psychophysiological responses in the diagnosis of posttraumatic stress disorder in Vietnam veterans. J Nerv Ment Dis 1991; 179: 97-101.

[135] Shalev A, Orr S, Peri T, Schreiber S, Pitman R. Physiologic responses to loud tones in Israeli patients with post-traumatic stress disorder. Arch Gen Psychiatry 1992; 49: 870-875.

[136] Orr S, Lasko N, Shalev A, Pitman R. Physiologic responses to loud tones in Vietnam veterans with posttraumatic stress disorder. J Abnorm Psychol 1995; 104: 75-82.

[137] Orr SP, Roth WT. Psychophysiological assessment: clinical applications for PTSD. J Affect Disord 2000; 61(3): 225-240.

[138] Rothbaum BO, Kozak MJ, Foa EB, Whitaker DJ. Post-traumatic stress disorder in rape victims: autonomic habituation to auditory stimuli. J Trauma Stress 2001; 14(2): 283-293. Available from: http://dx.doi.org/10. 1023/A:1011160800958.

[139] Halligan SL, Michael T, Wilhelm FH, Clark DM, Ehlers A. Reduced heart rate responding to trauma reliving in trauma survivors with PTSD: correlates and consequences. J Trauma Stress 2006; 19(5): 721-734. Available from: http://dx.doi.org/10.1002/jts.20167.

[140] Gerardi R, Blanchard E, Kolb L. Ability of Vietnam veterans to dissimulate a psychophysiological assessment for post-traumatic stress disorder. Behav Ther 1989; 20: 229-243.

[141] Casada JH, Amdur R, Larsen R, Liberzon I. Psychophysiologic responsivity in posttraumatic stress disorder: generalized hyperresponsiveness versus trauma specificity. Biol Psychiatry 1998; 44(10): 1037-1044.

[142] Casada JH, Roache JD. Dissociation of physiology and behavior in PTSD. Int J Psychophysiol 2006; 62(2): 243-248. Available from: http://dx.doi.org/10.1016/j. ijpsycho.2006.04.005.

[143] Brende J. Electrodermal responses in post-traumatic syndromes: A pilot study of cerebral hemisphere functioning in Vietnam veterans. J Nerv Ment Dis 1982; 170: 352-361.

[144] Boudewyns P, Hyer L. Physiological response to combat memories and preliminary treatment outcome in Vietnam veteran PTSD patients treated with direct therapeutic exposure. Behav Ther 1990; 21: 63-87.

[145] Murburg M. The psychobiology of post-traumatic stress disorder: An overview. Ann N Y Acad Sci 1997; 821: 352-358.

[146] LeDoux J. Emotion, memory and the brain. Sci Am 2002; 12: 6271.

[147] McGaugh J. Memory consolidation and the amygdala: A systems perspective. Trends Neurosci 2002; 25: 456-461. 
[148] Pitman R, Sanders K, Zusman R, Healy A, Cheema F, Lasko N, et al. Pilot study of secondary prevention of posttraumatic stress disorder with propranolol. Biol Psychiatry 2002; 51: 189-192.

[149] Pitman R. Overview of biological themes in PTSD. Ann N Y Acad Sci 1997; 821: 1-9.

[150] Burges-Watson IP, Hoffman L, Wilson GV. The neuropsychiatry of post-traumatic stress disorder. Br J Psychiatry 1988; 152(2): 164-173. Available from: http: //bjp.rcpsych.org/cgi/content/abstract/152/2/164.

[151] Everly G. A Clinical Guide to the Treatment of the Human Stress Response. New York: Plenum Press; 1989.

[152] Everly G. Psychotraumatology: A two-factor formulation of posttraumatic stress. Integrative Physiological and Behavioural Science 1993; 28: 270-278.

[153] Bremner J, Randall R, Scott T, Bronen R, Seibyl J, Southwick S, et al. MRI-based measurement of hippocampal volume in patients with combat-related post-traumatic stress disorder. Am J Psychiatry 1995; 152: 973-981.

[154] Gray J. The Neuropsychology of Anxiety: An enquiry into the functions of the septo-hippocampal system. Oxford: Oxford University Press; 1982.

[155] Gray J. Precis of the neuropsychology of anxiety: An enquiry into the functions of the septo-hippocampal system. Behav Brain Sci 1982; 5: 469-534

[156] Bremner J, Randall P, Vermetten E, Staib L, Bronen R, Mazure C, et al. Magnetic resonance imaging-based measurement of hippocampal volume in posttraumatic stress disorder related to childhood physical and sexual abuse: A preliminary report. Biol Psychiatry 1997; 41: 23-32.

[157] Gurvits TV, Shenton ME, Hokama H, Ohta H, Lasko NB, Gilbertson MW, et al. Magnetic resonance imaging study of hippocampal volume in chronic, combat-related posttraumatic stress disorder. Biol Psychiatry 1996; 40(11): 1091-1099.

[158] Stein M, Hanna C, Koverola C, Torchia M, McClarty B. Structural brain changes in PTSD: Does trauma alter neuroanatomy? Ann N Y Acad Sci 1997; 821: 76-82.

[159] Baxter M, Chiba A. Cognitive functions of the basal forebrain. Curr Opin Neurobiol 1999; 9: 178-183.

[160] Strange BA, Fletcher P, Henson R, Friston K, Dolan RJ. Segregating the functions of human hippocampus. Proc Natl Acad Sci USA 1999; 96: 4034-4039.

[161] Lisman J, Otmakhova N. Storage, recall, and novelty detection of sequences by the hippocampus: Elaborating on the SOCRATIC model to account for normal and aberrant effects of dopamine. Hippocampus 2001; 11: 551-568

[162] Stern C, Sherman S, Kirchhoff B, Hasselmo M. Medial temporal and prefrontal contributions to working memory tasks with novel and familiar stimuli. Hippocampus 2001; 11:337-346.

[163] Strange BA, Dolan RJ. Adaptive anterior hippocampal responses to oddball stimuli. Hippocampus 2001; 11: 690-698.
[164] Vinogradova O. Hippocampus as comparator: role of the two input and two output systems of the hippocampus in selection and registration of information. Hippocampus 2001; 11: 578-598.

[165] Sala M, Perez J, Soloff P, di Nemi SU, Caverzasi E, Soares JC, et al. Stress and hippocampal abnormalities in psychiatric disorders. Eur Neuropsychopharmacol 2004; 14(5): 393-405. Available from: http: //dx.doi.org/10.1016/j.euroneuro.2003.12.005.

[166] Joëls M, Krugers H, Karst H. Stress-induced changes in hippocampal function. Prog Brain Res 2008; 167: 3-15. Available from: http://dx.doi.org/10.1016/ S0079-6123(07)67001-0.

[167] Bonne O, Brandes D, Gilboa A, Gomori JM, Shenton ME, Pitman RK, et al. Longitudinal MRI study of hippocampal volume in trauma survivors with PTSD. Am J Psychiatry 2001; 158(8): 12481251. Available from: http://ajp.psychiatryonline.org/cgi/content/ abstract/158/8/1248.

[168] Gilbertson M, Shenton M, Ciszewski A, Kasai K, Lasko N, Orr S, et al. Smaller hippocampal volume predicts pathologic vulnerability to psychological trauma. Nat Neurosci 2002; 5: 12421247.

[169] Neylan TC, Lenoci M, Rothlind J, Metzler TJ, Schuff N, Du AT, et al. Attention, learning, and memory in post-traumatic stress disorder. J Trauma Stress 2004; 17(1): 41-46. Available from: http://dx.doi.org/10.1023/B: JOTS.0000014675.75686.ee.

[170] Press GA, Amaral DG, Squire LR. Hippocampal abnormalities in amnesic patients revealed by high-resolution magnetic resonance imaging. Nature 1989; 341: 54-57.

[171] Bremner JD. Hypotheses and controversies related to effects of stress on the hippocampus: an argument for stress-induced damage to the hippocampus in patients with posttraumatic stress disorder. Hippocampus 2001; 11(2): 75-81, discussion 82-84.

[172] Schuff N, Neylan TC, Fox-Bosetti S, Lenoci M, Samuelson KW, Studholme C, et al. Abnormal Nacetylaspartate in hippocampus and anterior cingulate in posttraumatic stress disorder. Psychiatry Res 2008; 162(2): 147-157. Available from: http://dx.doi.org/10. 1016/j.pscychresns.2007.04.011

[173] Pitman RK. Hippocampal diminution in PTSD: more (or less?) than meets the eye. Hippocampus 2001; 11(2): 73-74, discussion 82-84.

[174] Sapolsky R. Chickens, eggs and hippocampal atrophy. Nat Neurosci 2002; 5: 1111-1113.

[175] Canive JM, Lewine JD, Orrison WW, Edgar CJ, Provencal SL, Davis JT, et al. MRI reveals gross structural abnormalities in PTSD. Ann N Y Acad Sci 1997; 821: 512-515.

[176] Rauch S, Shin L, Segal E, Pitman R, Carson M, Mc-Mullin K, et al. Selectively reduced regional cortical volumes in post-traumatic stress disorder. Neuroreport 2003; 14: 913-916.

[177] Pitman R. Post-traumatic stress disorder, hormones and memory. Biol Psychiatry 1989; 26: 221-223.

[178] Watanabe Y, Gould H, McEwen B. Stress induces atrophy of apical dendrites of hippocampal CA3 pyramidal neurons. Brain Res 1992; 588: 341-345. 
[179] Sapolsky R. Why stress is bad for your brain. Science 1996; 273 : 749-750.

[180] McEwen BS, Magarinos A. Stress effects on morphology and function of the hippocampus. Ann N Y Acad Sci 1997; 821: 271284.

[181] McEwen BS. Stress and hippocampal plasticity. Annu Rev Neurosci 1999; 22: 105-122.

[182] McEwen BS. Commentary on PTSD discussion. Hippocampus 2001; 11(2): 82-84.

[183] Yehuda R. Are glucocortoids responsible for putative hippocampal damage in PTSD? How and when to decide. Hippocampus 2001; 11(2): 85-89.

[184] Gale G, Anagnostaras S, Fanselow M. Cholinergic modulation of Pavlovian fear conditioning: Effects of intrahippocampal scopolamine infusion. Hippocampus 2001; 11: 371-376.

[185] Watanabe Y, Gould H, Cameron D, Daniels D, McEwen B. Phenytoin prevents stress-and corticosteroneinduced atrophy of CA3 pyramidal neurons. Hippocampus 1992; 2: 431-436.

[186] Watanabe Y, Gould H, Daniels D, Cameron D, McEwen B. Tianeptine attenuates stress-induced morphological changes in the hippocampus. Eur J Pharmacol 1992; 222: 157-162.

[187] Friedman A, Kaufer D, Pavlovsky L, Soreq H. Cholinergic excitation induces activity-dependent electrophysiological and transcriptional responses in hippocampal slices. J Physiol Paris 1998; 92(3-4): 329-335.

[188] Bremner J, Innis R, Ng C, Staib L, Salomon R, Bronen R, et al. Positron emission tomography measurement of cerebral metabolic correlates of yohimbine administration in combat-related posttraumatic stress disorder. Arch Gen Psychiatry 1997; 54: 246254 .

[189] Post R. Transduction of psychosocial stress into the neurobiology of recurrent affective disorder. Am J Psychiatry 1992; 149: 9991010 .

[190] Post R, Weiss S, Smith M, McCann U. Kindling versus quenching: Implications for the evolution and treatment of posttraumatic stress disorder. Ann N Y Acad Sci 1997; 821: 285-295.

[191] Gil T, Calev A, Greenberg D, Kugelmass S, Lerer B. Cognitive functioning in post-traumatic stress disorder. J Trauma Stress 1990; 3: $29-45$.

[192] Uddo M, Vasterling J, Brailey K, Sutker P. Memory and attention in combat-related post-traumatic stress disorder. Journal of Psychopathology and Behavioural Assessment 1993; 15: 43-52.

[193] Barrett DH, Green ML, Morris R, Giles WH, Croft JB. Cognitive functioning and posttraumatic stress disorder. Am J Psychiatry 1996; 153(11): 1492-1494.

[194] Gurvits TV, Gilbertson MW, Lasko NB, Orr SP, Pitman RK. Neurological status of combat veterans and adult survivors of sexual abuse PTSD. Ann N Y Acad Sci 1997; 821: 468-471.

[195] Gurvits TV, Gilbertson MW, Lasko NB, Tarhan AS, Simeon D, Macklin ML, et al. Neurologic soft signs in chronic posttraumatic stress disorder. Arch Gen Psychiatry 2000; 57(2): 181-186.
Available from: http: //archpsyc.amaassn.org/cgi/content/abstract/57/2/181.

[196] Jenkins MA, Langlais PJ, Delis DA, Cohen RA. Learning and memory in rape victims with posttraumatic stress disorder. Am J Psychiatry 1998; 155(2): 278-

279. Available from: http://ajp.psychiatryonline.org/cgi/ content/abstract/155/2/278.

[197] Jenkins MA, Langlais PJ, Delis DA, Cohen RA. Attentional dysfunction associated with posttraumatic stress disorder among rape survivors. Clin Neuropsychol 2000; 14(1): 7-12. Available from: $\quad \mathrm{http} / / / \mathrm{www}$. ingentaconnect.com/content/psych/clin/ 2000/00000014/00000001/art00002.

[198] Gilbertson MW, Gurvits TV, Lasko NB, Orr SP, Pitman RK. Multivariate assessment of explicit memory function in combat veterans with posttraumatic stress disorder. J Trauma Stress 2001; 14(2): 413-432. Available from: http://dx.doi.org/10.1023/A:1011181305501.

[199] Koenen KC, Driver KL, Oscar-Berman M, Wolfe J, Folsom S, Huang MT, et al. Measures of prefrontal system dysfunction in posttraumatic stress disorder. Brain Cogn 2001; 45(1): 64-78. Available from: http://dx.doi.org/ 10.1006/brcg.2000.1256.

[200] Samuelson KW, Neylan TC, Metzler TJ, Lenoci M, Rothlind J, Henn-Haase C, et al. Neuropsychological functioning in posttraumatic stress disorder and alcohol abuse. Neuropsychology 2006; 20(6): 716-726. Available from: http://dx.doi.org/10.1037/0894-4105.20.6.716.

[201] Crowell TA, Kieffer KM, Siders CA, Vanderploeg RD. Neuropsychological findings in combat-related posttraumatic stress disorder. Clin Neuropsychol 2002; 16(3): 310-321.

[202] Leskin LP, White PM. Attentional networks reveal executive function deficits in posttraumatic stress disorder. Neuropsychology 2007; 21(3): 275-284. Available from: http://dx.doi.org/10.1037/0894-4105.21.3.275.

[203] Everly G, Horton A. Neuropsychology of posttraumatic stress disorder: A pilot study. Percept Mot Skills 1989; 68: 807-810.

[204] Bremner J, Scott T, Delaney R, Southwick S, Mason J, Johnson D, et al. Deficits in short-term memory in post-traumatic stress disorder. Am J Psychiatry 1993; 150: 1015-1019.

[205] Gurvits TV, Lasko NB, Repak AL, Metzger LJ, Orr SP, Pitman RK. Performance on visuospatial copying tasks in individuals with chronic posttraumatic stress disorder. Psychiatry Res 2002; 112(3): 263-268. Available from: http://dx.doi.org/10.1016/S01651781(02)00234-2.

[206] Lewine JD, Canive JM, Orrison WW, Edgar CJ, Provencal SL, Davis JT, et al. Electrophysiological abnormalities in PTSD. Ann N Y Acad Sci 1997; 821: 508-511.

[207] Gillette G, Skinner R, Rasco L, Fielstein E, Davis D, Pawelak J, et al. Combat veterans with posttraumatic stress disorder exhibit decreased habituation of the P1 midlatency auditory evoked potential. Life Sci 1997; 61: 1421-1434. 
[208] Neylan TC, Fletcher D, Lenoci M, McCallin K, Weiss D, Schoenfeld F, et al. Sensory gating in chronic posttraumatic stress disorder: reduced auditory P50 suppression in combat veterans. Biol Psychiatry 1999; 46: 1656- 1664.

[209] Shalev A, Attias J, Bleich A, Shulman H, Kotler M, Shahar A. Audiological evaluation of nonalcoholic, drug-free posttraumatic stress disorder patients. Biol Psychiatry 1988; 24: 522-530.

[210] Chao L, Knight R. Contribution of human prefrontal cortex to delay performance. J Cogn Neurosci 1998; 10: 167-177.

[211] Morgan C, Grillon C. Abnormal mismatch negativity in women with sexual assault-related posttraumatic stress disorder. Biol Psychiatry 1999; 45: 827-832.

[212] McFarlane AC, Weber DL, Clark CR. Abnormal stimulus processing in posttraumatic stress disorder. Biol Psychiatry 1993; 34(5): 311-320. Available from: http: //dx.doi.org/10.1016/00063223(93)90088-U.

[213] Charles G, Hansenne M, Ansseau M, Pitchot W, Machowski R, Schittecatte M, et al. P300 in posttraumatic stress disorder. Neuropsychobiology 1995; 32: 72-74.

[214] Galletly CA, Clark CR, McFarlane AC, Weber DL. Working memory in posttraumatic stress disorder - an event-related potential study. J Trauma Stress 2001; 14(2): 295-309.

[215] Veltmeyer MD, Clark CR, McFarlane AC, Felmingham KL, Bryant RA, Gordon E. Integrative assessment of brain and cognitive function in post-traumatic stress disorder. J Integr Neurosci 2005; 4(1): 145-159. Available from: http://dx.doi.org/10.1142/S0219635205000719.

[216] Veltmeyer MD, McFarlane AC, Bryant RA, Mayo T, Gordon E, Clark CR. Integrative assessment of brain function in PTSD: brain stability and working memory. J Integr Neurosci 2006; 5(1): 123138. Available from: http://dx.doi.org/10.1142/S0219635206001057.

[217] Hanatani T, Sumi N, Taguchi S, Fujimoto O, Nan-No H, Takeda M. Event-related potentials in panic disorder and generalized anxiety disorder. Psychiatry Clin Neurosci 2005; 59(1): 83-88. Available from: http://dx.doi.org/ 10.1111/j.14401819.2005.01336.x.

[218] Pauli P, Amrhein C, Mühlberger A, Dengler W, Wiedemann G. Electrocortical evidence for an early abnormal processing of panicrelated words in panic disorder patients. Int J Psychophysiol 2005; 57(1): 33-41. Available from: http://dx.doi.org/10.1016/j.ijpsycho.2005.01.009.

[219] Clark CR, McFarlane AC, Weber DL, Battersby M. Enlarged frontal P300 to stimulus change in panic disorder. Biol Psychiatry 1996; 39(10): 845-856. Available from: http://dx.doi.org/10.1016/0006-3223(95)00288-X.

[220] Pauli P, Dengler W, Wiedemann G, Montoya P, Flor H, Birbaumer $\mathrm{N}$, et al. Behavioral and neurophysiological evidence for altered processing of anxiety-related words in panic disorder. J Abnorm Psychol 1997; 106(2): 213-220.

[221] Turan T, Esel E, Karaaslan F, Basturk M, Oguz A, Yabanoglu I. Auditory event-related potentials in panic and generalised anxiety disorders. Prog Neuropsychopharmacol Biol Psychiatry 2002; 26(1): 123-126.

[222] Windmann S, Sakhavat Z, Kutas M. Electrophysiological evidence reveals affective evaluation deficits early in stimulus processing in patients with panic disorder. J Abnorm Psychol 2002; 111(2): 357369.

[223] Wang J, Miyazato H, Randall M, Hokama H, Hiramatsu KI, Ogura C. The N200 abnormalities of auditory event-related potentials in patients with panic disorder. Prog Neuropsychopharmacol Biol Psychiatry 2003; 27(6): 1013-1021. Available from: http://dx.doi.org/10. 1016/S0278-5846(03)00169-6.

[224] Pauli P, Dengler W, Wiedemann G. Implicit and explicit memory processes in panic patients as reflected in behavioral and electrophysiological measures. J Behav Ther Exp Psychiatry 2005; 36(2): 111-127. Available from: http://dx.doi.org/10.1016/j.jbtep.2004.08.003.

[225] Boudarene M, Timsit-Berthier M. Interest of events-related potentials in assessment of posttraumatic stress disorder. Ann N Y Acad Sci 1997; 821: 494-498.

[226] Näätänen R. Attention and Brain Function. Hillsdale NJ: Lawrence Erlbaum Associates; 1992.

[227] Duncan-Johnson C, Donchin E. On quantifying surprise: The variation in event-related potentials with subjective probability. Psychophysiology 1977; 14: 456-467.

[228] Johnson R. The amplitude of the P300 component of the eventrelated potential: Review and synthesis. In: Ackles PK, Jennings JR, Coles MGH, editors. Advances in Psychophysiology. vol. 3. Greenwich, CT: JAI Press; 1988. p. 69-137.

[229] Weber DL, Clark CR, McFarlane AC, Moores KA, Morris P, Egan GF. Abnormal frontal and parietal activity during working memory updating in post-traumatic stress disorder. Psychiatry Res 2005; 140(1): 27-44. Available from: http://dx.doi.org/10.1016/j.pscychresns. 2005.07.003.

[230] Clark CR, Geffen GM, Geffen LB. Catecholamines and attention. I: Animal and clinical studies. Neurosci Biobehav Rev 1987; 11(4): 341-352. Available from: http://dx.doi.org/10.1016/S01497634(87)80006-4.

[231] Clark CR, Geffen GM, Geffen LB. Catecholamines and attention. II: Pharmacological studies in normal humans. Neurosci Biobehav Rev 1987; 11(4): 353-364. Available from: http://dx.doi.org/10.1016/S0149-7634(87) 80007-6.

[232] Shelley AM, Catts SV, Ward PB, Andrews S, Mitchell P, Michie P, et al. The effect of decreased catecholamine transmission on ERP indices of selective attention. Neuropsychopharmacology 1997; 16(3): 202-210. Available from: http://dx.doi.org/10.1016/S0893133X(96) 00190-X.

[233] Turetsky BI, Fein G. Alpha2-noradrenergic effects on ERP and behavioral indices of auditory information processing. Psychophysiology 2002; 39(2): 147-157. Available from: http://dx.doi.org/10.1017/ S0048577202991298.

[234] Llorente AM, Voigt RG, Jensen CL, Berretta MC, Fraley JK, Heird WC. Performance on a Visual Sustained Attention and 
Discrimination Task is Associated with Urinary Excretion of Norepineprhine Metabolite in Children with AttentionDeficit/Hyperactivity Disorder (AD/HD). Clin Neuropsychol 2006; 20(1): 133-144. Available from: http://dx.doi.org/10.1080/ 13854040490888495 .

[235] Metzger L, Orr S, Lasko N, Berry N, Pitman R. Evidence for diminished P3 amplitudes in PTSD. Ann N Y Acad Sci 1997; 821: 499-503.

[236] Galletly CA, McFarlane AC, Clark R. Differentiating cortical patterns of cognitive dysfunction in schizophrenia and posttraumatic stress disorder. Psychiatry Res 2008; 159(1-2): 196206. Available from: http://dx.doi. org/10.1016/j.psychres.2007.04.001.

[237] Kimble M, Kaloupek D, Kaufman M, Deldin P. Stimulus novelty differentially affects attentional allocation in PTSD. Biol Psychiatry 2000; 47: 880-890.

[238] Grillon C, Ameli R. P300 assessment of anxiety effects on processing novel stimuli. Int J Psychophysiol 1994; 17(3): 205-217.

[239] Semple WE, Goyer P, McCormick R, Morris E, Compton B, Muswick G, et al. Preliminary report: brain blood flow using PET in patients with posttraumatic stress disorder and substance-abuse histories. Biol Psychiatry 1993; 34(1-2): 115-118.

[240] Semple WE, Goyer PF, McCormick R, Compton-Toth B, Morris E, Donovan $\mathrm{B}$, et al. Attention and regional cerebral blood flow in posttraumatic stress disorder patients with substance abuse histories. Psychiatry Res 1996; 67(1): 17-28. Available from: http://dx.doi.org/ 10.1016/0925-4927(96)02735-7.

[241] Semple WE, Goyer PF, McCormick R, Donovan B, Muzic RF, Rugle L, et al. Higher brain blood flow at amygdala and lower frontal cortex blood flow in PTSD patients with comorbid cocaine and alcohol abuse compared with normals. Psychiatry 2000; 63(1): 65-74.
[242] Posner MI, Raichle M. Images of Mind. New York: Scientific American Library; 1994.

[243] Corbetta M, Shulman GL. Control of Goal-Directed and StimulusDriven Attention in the Brain. Nat Rev Neurosci 2002; 3(3): 201215. Available from: http: //dx.doi.org/10.1038/nrn755.

[244] Shaw ME, Strother SC, McFarlane AC, Morris P, Anderson J, Clark CR, et al. Abnormal functional connectivity in posttraumatic stress disorder. Neuroimage 2002; 15(3): 661-674. Available from: http://dx.doi.org/10. 1006/nimg.2001.1024.

[245] Clark CR, McFarlane AC, Morris P, Weber DL, Sonkkilla C, Shaw $\mathrm{M}$, et al. Cerebral function in post-traumatic stress disorder during verbal working memory updating: a positron emission tomography study. Biol Psychiatry 2003; 53(6): 474-481. Available from: http://dx.doi.org/10.1016/S0006-3223(02)01505-6.

[246] Clark CR, Egan GF, McFarlane AC, Morris P, Weber D, Sonkkilla $\mathrm{C}$, et al. Updating working memory for words: A PET activation study. Hum Brain Mapp 2000; 9(1): 42-54. Available from: http://dx.doi.org/10.1002/(SICI) 1097-0193(2000)9:1<42::AIDHBM5 $>3.0 . \mathrm{CO} ; 2-6$.

[247] McCarthy G. Functional neuroimaging of memory. The Neuroscientist 1995; 1: 155-163.

[248] Passingham R. Attention to action. Philos Trans R Soc Lond B Biol Sci 1996; 351: 1473-1479.

[249] Ungerleider L, Courtney S, Haxby J. A neural system for human visual working memory. Proc Natl Acad Sci USA 1998; 95: 883890.

[250] Smith E, Jonides J. Storage and executive processes in the frontal lobes. Science 1999; 283: 1657-1661.

[251] Gerardi RJ, Keane TM, Cahoon BJ, Klauminzer GW. An in vivo assessment of physiological arousal in posttraumatic stress disorder. J Abnorm Psychol 1994; 103(4): 825-827.

Received: October 24, 2007

Revised: May 05, 2008

Accepted: May 22, 2008

C. Darren L. Weber; Licensee Bentham Open.

This is an open access article licensed under the terms of the Creative Commons Attribution Non-Commercial License (http://creativecommons.org/licenses/by$\mathrm{nc} / 3.0 /$ ), which permits unrestricted, non-commercial use, distribution and reproduction in any medium, provided the work is properly cited. 